\title{
Capital Accumulation and Dynamic Gains from Trade*
}

\author{
B. Ravikumar ${ }^{\dagger} \quad$ Ana Maria Santacreu ${ }^{\ddagger} \quad$ Michael Sposi ${ }^{\S}$ \\ February 14, 2017
}

\begin{abstract}
We compute welfare gains from trade in a dynamic, multicountry model with capital accumulation. We examine transition paths for 93 countries following a permanent, uniform, unanticipated trade liberalization. Both the relative price of investment and the investment rate respond to changes in trade frictions. Relative to a static model, the dynamic welfare gains in a model with balanced trade are three times as large. The gains including transition are 60 percent of those computed by comparing only steady states. Trade imbalances have negligible effects on the cross-country distribution of dynamic gains. However, relative to the balanced-trade model, small, less-developed countries accrue the gains faster in a model with trade imbalances by running trade deficits in the short run but have lower consumption in the long-run. In both models most of the dynamic gains are driven by capital accumulation.
\end{abstract}

JEL codes: E22, F11, O11

Keywords: Welfare gains from trade; Dynamic gains; Capital accumulation; Trade imbalances

*This paper benefited from comments by Lorenzo Caliendo, Jonathan Eaton, Fernando Parro, Kim Ruhl, Mariano Somale, Felix Tintelnot, Kei-Mu Yi, and Jing Zhang. We are grateful to seminar audiences at Arizona State University, The Federal Reserve Bank of Dallas, Penn State University, Purdue University, the University of Texas-Austin, and conference audiences at the EIIT, Midwest Macro, Midwest Trade, RIDGE Workshop on Trade and Firm Dynamics, UTDT Economics Conference, the Society for Economic Dynamics, and the System Committee for International Economic Analysis. The views in this paper are those of the authors and do not necessarily reflect the views of the Federal Reserve Banks of Dallas, St. Louis, or the Federal Reserve System.

${ }^{\dagger}$ Federal Reserve Bank of St. Louis, P.O. Box 442, St. Louis, MO 63166. b.ravikumar@wustl.edu

${ }^{\ddagger}$ Federal Reserve Bank of St. Louis, P.O. Box 442, St. Louis, MO 63166. am.santacreu@gmail.com

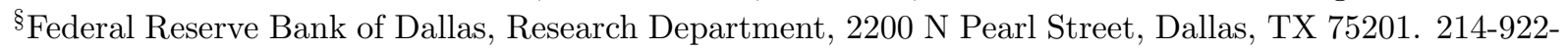
5881. michael.sposi@dal.frb.org 


\section{Introduction}

How large are the welfare gains from trade? This is an old and important question. This question has typically been answered in static settings by computing the change in real income from an observed equilibrium to a counterfactual equilibrium. In such computations, the factors of production and technology in each country are held fixed and the change in real income is entirely due to the change in each country's trade share that responds to a change in trade frictions. Recent examples include Arkolakis, Costinot, and RodríguezClare (2012) (ACR hereafter), who compute the welfare cost of autarky, and Waugh and Ravikumar (2016), who compute the welfare gains from frictionless trade.

By design, the above computations cannot distinguish between static and dynamic gains. We calculate welfare gains from trade in a dynamic multicountry Ricardian model where international trade affects the capital stock in each period. Our environment is a version of Eaton and Kortum (2002) embedded in a two-sector neoclassical growth model. There is a continuum of tradable intermediate goods. Each country is endowed with an initial stock of capital. Investment goods, produced using tradables, augment the stock of capital. Two key channels in our model, the relative price of investment and the investment rate, respond to changes in trade frictions. The relative price channel affects the steady state and the investment rate channel affects the transition dynamics.

We calibrate the steady state of the model under balanced trade to reproduce the observed bilateral trade flows across 93 countries. We then conduct a counterfactual exercise in which there is an unanticipated, uniform, and permanent reduction in trade frictions for all countries. We compute the exact levels of endogenous variables along the transition path from the calibrated steady state to the counterfactual steady state and calculate the welfare gains using a consumption-equivalent measure as in Lucas (1987).

We find that (i) static calculations understate the gains; in our model, the gains across steady states are five times as large as those in a static model and the dynamic gains with transition are three times as large. (ii) Consumption dynamics are approximately the same across countries, except for scale, and the dynamic gain is proportional to the static gain, as in Anderson, Larch, and Yotov (2015). (iii) Comparing only steady states overstates the gains from trade; the dynamic gains accrue gradually and are about 60 percent of steadystate gains for every country. (iv) Both the dynamic gains and the steady-state gains differ across countries by a factor of 5 ; for instance, the dynamic gain is 11 percent for the United States and is 56 percent for Belize. 
In a static model, consumption equals output and the gain from trade is pinned down by the change in output. Since factors of production are held fixed, the gain is equal to the change in Total Factor Productivity (TFP). In our model, the change in output is driven by both the change in TFP and the change in capital. In steady state, consumption is proportional to output, so the steady-state gains correspond to changes in TFP and capital, and are larger than those in a static model. Almost 80 percent of the steady-state gains are accounted for by the increase in capital. Along the transition, the dynamic path for consumption is determined by an intertemporal Euler equation and consumption is not proportional to output. However, both capital and output increase, yielding a higher level of consumption. As a result, dynamic gains are larger than static gains. Since capital accumulates gradually, neither consumption nor output reach their steady-state values instantaneously, so the dynamic gains are lower than the steady-state gains. The dynamics in consumption thus introduce differences between the short-run and the long-run gains from trade as well as differences between static and dynamic gains.

The two key channels of our model are quantitatively important for the dynamic gains from trade. Trade liberalization reduces the relative price of investment, which increases the investment rate, resulting in a higher stock of capital and higher consumption. In contrast, if the relative price was fixed, consumption would have to decrease in order to achieve the same increase in investment. Trade liberalization also increases TFP, which in turn increases the rate of return to capital. As a result, households respond by increasing their investment rate. This response by households is absent when the investment rate is fixed. The dynamic gains in our model are almost twice as large as the gains when the investment rate and the relative price of investment are both fixed; the steady-state gains are 2.6 times as large.

In our model, trade balance in each period limits consumption smoothing since it prevents borrowing and lending across countries. Thus, our gains could be an underestimate. We correct this by allowing countries to buy and sell one-period bonds, thereby endogenizing trade imbalances. A key difference between the two models is that in the model with balanced trade the rate of return to capital differs across countries along the counterfactual transition path, with small, less-developed countries having higher returns. Borrowing and lending across countries eliminates the rate of return differences: Resources flow from large, developed countries to small, less-developed countries until the returns are equalized. Therefore, small, less-developed countries run a trade deficit in the short run and then converge to a steady state with a trade surplus as they pay down their debt. The opposite is true for large, developed countries 
We consider the same counterfactual reduction in trade frictions as in the model with balanced trade. In the model with trade imbalances, the dynamic welfare gains are almost the same as in the model with balanced trade. In both models, most of the dynamic gains are driven by capital accumulation. Thus, we find larger gains relative to Reyes-Heroles (2016) who studies trade imbalances in a model without capital. In contrast to the model with balanced trade, the rate at which the dynamic gains accrue along the transition in the model with trade imbalances differs across countries. Small, less-developed countries frontload consumption, while large, developed countries do the opposite. Hence, the short-run gains for small, less-developed countries are larger than those for large, developed countries.

The cross-country distribution of steady-state gains differs between the two models. Relative to the balanced trade model, steady-state gains are larger for large, developed countries and smaller for small, less-developed countries. For instance, the gain across steady states for Belize is 92 percent in the balanced trade model and is 71 percent in the model with trade imbalances; the corresponding steady-state gains for the United States are 18 and 20 percent, respectively. In contrast to the model with balanced trade, the dynamic gain in the model with trade imbalance is not proportional to the steady-state gain.

Our two channels are quantitatively important in the model with trade imbalances as well. With fixed investment rate and relative price of investment, the median dynamic gain is 16 percent; for the same country, the gain is 25 percent when they are both endogenous. Our dynamic gains are also larger than those in Sposi (2012) who has a model with endogenous trade imbalances but an exogenous nominal investment rate.

We build on the framework by Anderson, Larch, and Yotov (2015) who compute transitional dynamics with fixed investment rate and relative price of investment. Their transition path is the solution to a sequence of static problems. We endogenize the relative price of investment and the investment rate, so the current allocations and prices depend on the entire path of prices and trade frictions. Hence, we have to simultaneously solve a system of second-order, non-linear difference equations. Quantitatively, the increase in investment rate for the country with the median gain is 81 percent across steady states in our model. When the relative price of investment and the investment rate do not respond to changes in trade frictions, the increase is zero.

Our solution method generalizes the algorithm of Alvarez and Lucas (2007) to a dynamic environment by iterating on a subset of prices using excess demand equations. The method delivers the entire transition path for 93 countries for the balanced trade model in less than 4 hours on a basic laptop computer. It takes 40 hours to solve the model with trade 
imbalances since the state space includes net foreign asset positions as well as capital stocks ${ }^{1}$ Our method provides an exact dynamic path whereas Alvarez and Lucas (2016) approximate the dynamics by linearizing around the steady state. They study the consequences of small changes in tariffs, but their method might be inaccurate for computing transitional dynamics in cases of large trade liberalizations. For instance, we find that the dynamic gain for the median-gain country increases exponentially with reductions in trade frictions: The gains are 3, 27, 115 percent when trade frictions are reduced by 10, 50, and 90 percent, respectively. Caliendo, Dvorkin, and Parro (2015) and Eaton, Kortum, Neiman, and Romalis (2016) use the so-called hat algebra approach to compute period-over-period changes in endogenous variables due to changes in exogenous variables.2 An advantage of their approach (and their counterfactuals) is that it requires knowledge of levels of only a few endogenous variables and parameters. However, computing counterfactuals such as frictionless trade requires knowing the initial levels of several endogenous variables and all of the structural parameters. We solve for the transition path in levels. An advantage of our approach is that it helps us validate the implications of the model before we run the counterfactual. Specifically, our model is consistent with the observed bilateral trade flows and cross-country distribution of several variables, such as prices and investment rates.

Eaton, Kortum, Neiman, and Romalis (2016) compute the counterfactuals by solving the planner's problem under the assumption that the Pareto weights remain constant. That is, each country's share in world consumption is assumed to be the same in the benchmark and in the counterfactual. Instead, we solve for the competitive equilibrium and find that each country's share in world consumption changes in the counterfactual. For example, Belize's share increases by a factor of 3 across steady states, whereas the U.S.'s share decreases. These changes in consumption shares affect welfare gains since the social planner would allocate more resources to Belize, relative to the case in which Pareto weights are constant.

In related literature on dynamics in international trade, Baldwin (1992) and Alessandria, Choi, and Ruhl (2014) study welfare gains in two-country models with capital accumulation and balanced trade (see also Brooks and Pujolas, 2016). Kehoe, Ruhl, and Steinberg (2016) study trade imbalances in a two-country model with capital accumulation. Our multicountry model reveals a nonlinear relationship between the rate of capital accumulation from the

\footnotetext{
${ }^{1}$ Our algorithm uses gradient-free updating rules that are computationally less demanding than the nonlinear solvers used in recent dynamic models of trade (see, e.g., Eaton, Kortum, Neiman, and Romalis, 2016. Kehoe, Ruhl, and Steinberg, 2016).

2 Zylkin (2016) uses an approach similar to hat algebra to study how China's integration into the world economy had an effect on the rest of the world. His approach is different in that he computes the change of each variable from its baseline sequence to its counterfactual sequence.
} 
calibrated to the counterfactual steady state and trade imbalances: The rate of accumulation increases exponentially with short-run trade deficits.

Our paper is also related to recent studies that use "sufficient statistics" to measure changes in welfare by changes in income, which are completely described by changes in the home trade share (ACR). Our model with capital as an endogenous factor of production yields a sufficient statistics formula for steady-state gains, in which the change in capital and the change in TFP and, hence, the change in income, are fully characterized by the change in the home trade share. However, our formula is not valid along the transition

path since (i) consumption is not proportional to income and (ii) the home trade share changes immediately whereas consumption changes gradually along with capital and output. Moreover, in our model with trade imbalances, changes in the home trade share are not sufficient to characterize the changes in welfare even across steady states. This is because (i) the elasticity of income with respect to the home trade share depends on the level of the trade imbalance, unlike the balanced trade case where the elasticity is constant, and (ii) changes in income are not the correct measure for steady-state gains since consumption is not proportional to income.

The rest of the paper proceeds as follows. Section 2 presents the model with balanced trade. Section 3 describes the calibration while Section 4 reports the results from the counterfactual exercise. Section 5 explores the quantitative implications in the model with endogenous trade imbalances, and Section 6 concludes.

\section{Model}

There are $I$ countries indexed by $i=1, \ldots, I$ and time is discrete, running from $t=1, \ldots, \infty$. There are three sectors: consumption, investment, and intermediates, denoted by $c, x$, and $m$, respectively. Neither consumption goods nor investment goods are tradable. There is a continuum of intermediate varieties that are tradable. Production of all goods is carried out by perfectly competitive firms. As in Eaton and Kortum (2002), each country's efficiency in producing each intermediate variety is a realization of a random draw from a countryspecific distribution. Trade in intermediate varieties is subject to iceberg costs. Each country purchases each intermediate variety from its lowest-cost supplier and all of the varieties are aggregated into a composite intermediate good. The composite good is used as an input along with capital and labor to produce the consumption good, the investment good, and the intermediate varieties. 
Each country has a representative household. The household owns its country's stock of capital and labor, which it inelastically supplies to domestic firms, and purchases consumption and investment goods from the domestic firms. We assume that trade is balanced in each period; we endogenize trade imbalances in Section 5 .

\section{$2.1 \quad$ Endowments}

The representative household in country $i$ is endowed with a labor force of size $L_{i}$ in each period and an initial stock of capital, $K_{i 1}$.

\subsection{Technology}

There is a unit interval of varieties in the intermediates sector. Each variety within the sector is tradable and is indexed by $v \in[0,1]$.

Composite good Within the intermediates sector, all of the varieties are combined with constant elasticity to construct a sectoral composite good according to

$$
M_{i t}=\left[\int_{0}^{1} q_{i t}(v)^{1-1 / \eta} d v\right]^{\eta /(\eta-1)},
$$

where $\eta$ is the elasticity of substitution between any two varieties. The term $q_{i t}(v)$ is the quantity of good $v$ used by country $i$ to construct the composite good at time $t$ and $M_{i t}$ is the quantity of the composite good available in country $i$ to be used as an input.

Varieties Each variety is produced using capital, labor, and the composite good. The technologies for producing each variety are given by

$$
Y_{m i t}(v)=z_{m i}(v)\left(K_{m i t}(v)^{\alpha} L_{m i t}(v)^{1-\alpha}\right)^{\nu_{m}} M_{m i t}(v)^{1-\nu_{m}} .
$$

The term $M_{m i t}(v)$ denotes the quantity of the composite good used by country $i$ as an input to produce $Y_{m i t}(v)$ units of variety $v$, while $K_{m i t}(v)$ and $L_{m i t}(v)$ denote the quantities of capital and labor used.

The parameter $\nu_{m} \in[0,1]$ denotes the share of value added in total output and $\alpha$ denotes capital's share in value added. These parameters are constant across countries and over time.

The term $z_{m i}(v)$ denotes country $i$ 's productivity for producing variety $v$. Following Eaton and Kortum (2002), the productivity draw comes from independent Fréchet distributions 
with shape parameter $\theta$ and country-specific scale parameter $T_{m i}$, for $i=1,2, \ldots, I$. The c.d.f. for productivity draws in country $i$ is $F_{m i}(z)=\exp \left(-T_{m i} z^{-\theta}\right)$.

In country $i$ the expected value of productivity is $\gamma^{-1} T_{m i}^{\frac{1}{\theta}}$, where $\gamma=\Gamma\left(1+\frac{1}{\theta}(1-\eta)\right)^{\frac{1}{1-\eta}}$ and $\Gamma(\cdot)$ is the gamma function, and $T_{m i}^{\frac{1}{\theta}}$ is the fundamental productivity in country $i$. If $T_{m i}>T_{m j}$, then on average, country $i$ is more efficient than country $j$ at producing intermediate varieties. A smaller $\theta$ implies more room for specialization and, hence, more gains from trade.

Consumption good Each country produces a final consumption good using capital, labor, and intermediates according to

$$
Y_{c i t}=A_{c i}\left(K_{c i t}^{\alpha} L_{c i t}^{1-\alpha}\right)^{\nu_{c}} M_{c i t}^{1-\nu_{c}}
$$

The terms $K_{c i t}, L_{c i t}$, and $M_{c i t}$ denote the quantities of capital, labor, and the composite good used by country $i$ to produce $Y_{c i t}$ units of consumption at time $t$. The parameters $\alpha$ and $\nu_{c}$ are constant across countries and over time. The term $A_{c i}$ captures country $i$ 's productivity in the consumption goods sector- this term varies across countries.

Investment good Each country produces an investment good using capital, labor, and intermediates according to

$$
Y_{x i t}=A_{x i}\left(K_{x i t}^{\alpha} L_{x i t}^{1-\alpha}\right)^{\nu_{x}} M_{x i t}^{1-\nu_{x}}
$$

The terms $K_{x i t}, L_{x i t}$, and $M_{x i t}$ denote the quantities of capital, labor, and the composite good used by country $i$ to produce $Y_{x i}$ units of investment at time $t$. The parameters $\alpha$ and $\nu_{x}$ are constant across countries and over time. The term $A_{x i}$ captures country $i$ 's productivity in the investment goods sector - this term varies across countries.

\subsection{Trade}

International trade is subject to frictions that take the iceberg form. Country $i$ must purchase $d_{i j} \geq 1$ units of any intermediate variety from country $j$ in order for one unit to arrive; $d_{i j}-1$ units melt away in transit. As a normalization, we assume that $d_{i i}=1$ for all $i$. 


\section{$2.4 \quad$ Preferences}

The representative household's lifetime utility is given by

$$
\sum_{t=1}^{\infty} \beta^{t-1} L_{i} \frac{\left(C_{i t} / L_{i}\right)^{1-1 / \sigma}}{1-1 / \sigma}
$$

where $C_{i t} / L_{i}$ is consumption per capita in country $i$ at time $t, \beta \in(0,1)$ denotes the period discount factor and $\sigma$ denotes the intertemporal elasticity of substitution. Both parameters are constant across countries and over time.

Capital accumulation The representative household enters period $t$ with $K_{i t}$ units of capital, which depreciates at the rate $\delta$. Investment, $X_{i t}$, adds to the stock of capital.

$$
K_{i t+1}=(1-\delta) K_{i t}+X_{i t}
$$

Budget constraint The representative household earns income by supplying capital and labor inelastically to domestic firms earning a rental rate $r_{i t}$ on capital and a wage rate $w_{i t}$ on labor. The household purchases consumption at the price $P_{c i t}$ and purchases investment at the price $P_{x i t}$. The budget constraint is given by

$$
P_{c i t} C_{i t}+P_{x i t} X_{i t}=r_{i t} K_{i t}+w_{i t} L_{i}
$$

\subsection{Equilibrium}

A competitive equilibrium satisfies the following conditions: (i) taking prices as given, the representative household in each country maximizes its lifetime utility subject to its budget constraint and technology for accumulating capital, (ii) taking prices as given, firms maximize profits subject to the available technologies, (iii) intermediate varieties are purchased from their lowest-cost provider subject to the trade frictions, and (iv) all domestic markets clear and trade is balanced in each period. At each point in time, we take world GDP as the numéraire: $\sum_{i} r_{i t} K_{i t}+w_{i t} L_{i}=1$ for all $t$. We describe each equilibrium condition in more detail in Appendix A. 


\subsection{Welfare Analysis}

We measure changes in welfare using consumption equivalent units as in Lucas (1987). In static models these changes are equal to changes in income since consumption equals income. In our model, consumption is proportional to income in steady state and the ratio of consumption to income, $1-\frac{\alpha \delta}{\frac{1}{\beta}-(1-\delta)}$, is the same across countries.

We measure the steady-state gains in country $i, \lambda_{i}^{s s}$, according to:

$$
1+\frac{\lambda_{i}^{s s}}{100}=\frac{C_{i}^{\star \star}}{C_{i}^{\star}}=\frac{y_{i}^{\star \star}}{y_{i}^{\star}}
$$

where $C_{i}^{\star}$ and $y_{i}^{\star}$ are the consumption and per capita income in the initial steady state in country $i$ and $C_{i}^{\star \star}$ and $y_{i}^{\star \star}$ are the consumption and per capita income in the counterfactual steady state in country $i$.

Along the transition path, consumption might not be proportional to income. The $d y$ namic gain in country $i$ is measured by $\lambda_{i}^{d y n}$ that solves:

$$
\sum_{t=1}^{\infty} \beta^{t-1} L_{i} \frac{\left(\left(1+\frac{\lambda_{i}^{d y n}}{100}\right) C_{i}^{\star} / L_{i}\right)^{1-1 / \sigma}}{1-1 / \sigma}=\sum_{t=1}^{\infty} \beta^{t-1} L_{i} \frac{\left(\tilde{C}_{i t} / L_{i}\right)^{1-1 / \sigma}}{1-1 / \sigma}
$$

where $\tilde{C}_{i t}$ is the consumption at time $t$ in the counterfactual. Note that in steady state, $\tilde{C}_{i t}$ is constant over time and equation (2) collapses to equation (1).

Computing the dynamic gains requires computing the transition path for consumption, which depends on the path for income. We define real income per capita in our model as $y_{i t} \equiv \frac{r_{i t} K_{i t}+w_{i t} L_{i t}}{P_{c i t} L_{i t}}$. Appendix $\mathrm{D}$ shows that

$$
y_{i t} \propto A_{c i}\left(\frac{T_{m i}}{\pi_{i i t}}\right)^{\frac{1-\nu_{c}}{\theta \nu_{m}}}\left(\frac{K_{i t}}{L_{i}}\right)^{\alpha}
$$

Trade liberalization results in an immediate and permanent drop in the home trade shares and, hence, permanently higher measured TFP on impact. Capital stock does not change on impact, but it increases gradually along the transition path. The rate of accumulation depends on the two channels in our model: (i) endogenous investment rate and (ii) endogenous relative price of investment.

The increase in TFP yields a higher rate of return to capital, which increases the investment rate. The optimal investment rate is governed by the intertemporal Euler equation: 


$$
\frac{C_{i t+1}}{C_{i t}}=\beta^{\sigma}\left(1+\frac{r_{i t+1}}{P_{x i t+1}}-\delta\right)^{\sigma}\left(\frac{P_{x i t+1} / P_{c i t+1}}{P_{x i t} / P_{c i t}}\right)^{\sigma} .
$$

The relative price of investment is given by

$$
\frac{P_{x i t}}{P_{c i t}} \propto\left(\frac{A_{c i}}{A_{x i}}\right)\left(\frac{T_{m i}}{\pi_{i i t}}\right)^{\frac{\nu_{x}-\nu_{c}}{\theta \nu_{m}}}
$$

The lower home trade share implies a lower relative price of investment since $\nu_{x}<\nu_{c}$, so the household can allocate a larger share of income toward investment without sacrificing consumption.

Combining the Euler equation with the budget constraint and the capital accumulation technology, the equilibrium law of motion for capital must obey the following equation in every country:

$$
\begin{aligned}
& \left(1+\frac{r_{i t+1}}{P_{x i t+1}}-\delta\right)\left(\frac{P_{x i t+1}}{P_{c i t+1}}\right) K_{i t+1}+\left(\frac{w_{i t+1}}{P_{c i t+1}}\right) L_{i}-\left(\frac{P_{x i t+1}}{P_{c i t+1}}\right) K_{i t+2} \\
& =\beta^{\sigma}\left(1+\frac{r_{i t+1}}{P_{x i t+1}}-\delta\right)^{\sigma}\left(\frac{P_{x i t+1} / P_{c i t+1}}{P_{x i t} / P_{c i t}}\right)^{\sigma} \\
& \times\left[\left(1+\frac{r_{i t}}{P_{x i t}}-\delta\right)\left(\frac{P_{x i t}}{P_{c i t}}\right) K_{i t}+\left(\frac{w_{i t}}{P_{c i t}}\right) L_{i}-\left(\frac{P_{x i t}}{P_{c i t}}\right) K_{i t+1}\right] .
\end{aligned}
$$

Note that the dynamics of capital in country $i$ depend on the capital stocks in all other countries due to trade. The dynamics are pinned down by the solution to a system of $I$ simultaneous, second-order, nonlinear difference equations. The optimality conditions for the firms combined with the relevant market clearing conditions and trade balance pin down the prices as a function of the capital stocks in all countries.

Equation (6) also reveals that a change in trade friction for any country at any point in time affects the dynamic path of all countries.

\section{Calibration}

We calibrate the parameters of the model to match several observations in 2011. Our assumption is that the world is in steady state at this time. Table C.1 provides the equilibrium conditions that describe the steady state in our model. Our technique for computing the steady-state is standard, while our method for computing the transition path between steady states is new. 
Our data covers 93 countries (containing 91 individual countries plus 2 regional country groups). Table F.1 in the appendix provides a list of the countries along with their 3-digit ISO codes. This set of countries accounts for 90 percent of world GDP as measured by the Penn World Tables version 8.1 (Feenstra, Inklaar, and Timmer, 2015, hereafter PWT 8.1) and for 84 percent of world trade in manufactures as measured by the UN Comtrade Database. Appendix $\mathrm{B}$ provides the details of our data.

\subsection{Common parameters}

The values for the common parameters are reported in Table 1. We use recent estimates of the trade elasticity by Simonovska and Waugh (2014) and set $\theta=4$. We set $\eta=2$ which satisfies the condition $1+\frac{1}{\theta}(1-\eta)>0$. This value plays no quantitative role in our results.

Table 1: Common parameters

\begin{tabular}{cll}
\hline \hline$\theta$ & Trade elasticity & 4 \\
$\eta$ & Elasticity of substitution between varieties & 2 \\
$\alpha$ & Capital's share in value added & 0.33 \\
$\beta$ & Annual discount factor & 0.96 \\
$\delta$ & Annual depreciation rate for stock of capital & 0.06 \\
$\sigma$ & Intertemporal elasticity of substitution & 0.67 \\
$\nu_{c}$ & Share of value added in final goods output & 0.91 \\
$\nu_{x}$ & Share of value added in investment goods output & 0.33 \\
$\nu_{m}$ & Share of value added in intermediate goods output & 0.28 \\
\hline
\end{tabular}

In line with the literature, we set the share of capital in value added to $\alpha=0.33$ Gollin, 2002), the discount factor to $\beta=0.96$, so that the steady-state real interest rate is about 4 percent, and the intertemporal elasticity of substitution to $\sigma=0.67$.

We compute $\nu_{m}=0.28$ by taking the cross-country average of the ratio of value added to gross output of manufactures. We compute $\nu_{x}=0.33$ by taking the cross-country average of the ratio of value added to gross output of investment goods.

Computing $\nu_{c}$ is slightly more involved since there is no clear industry classification for consumption goods. Instead, we infer this share by interpreting the national accounts through the lens of our model. We begin by noting that by combining firm optimization and market clearing conditions for capital and labor we get

$$
r_{i} K_{i}=\frac{\alpha}{1-\alpha} w_{i} L_{i} .
$$


In steady state, the Euler equation and the capital accumulation technology imply

$$
P_{x i} X_{i}=\frac{\delta \alpha}{\frac{1}{\beta}-(1-\delta)} \frac{w_{i} L_{i}}{1-\alpha}=\phi_{x} \frac{w_{i} L_{i}}{1-\alpha} .
$$

We compute $\phi_{x}$ by taking the cross-country average of the share of gross fixed capital formation in nominal GDP. The household's budget constraint then implies that

$$
P_{c i} C_{i}=\frac{w_{i} L_{i}}{1-\alpha}-P_{x i} X_{i}=\left(1-\phi_{x}\right) \frac{w_{i} L_{i}}{1-\alpha}
$$

Consumption in our model corresponds to the sum of private and public consumption, changes in inventories, and net exports. We use the trade balance condition together with the firm optimality and the market clearing conditions for sectoral output to obtain

$$
P_{m i} M_{i}=\left[\left(1-\nu_{x}\right) \phi_{x}+\left(1-\nu_{c}\right)\left(1-\phi_{x}\right)\right] \frac{w_{i} L_{i}}{1-\alpha}+\left(1-\nu_{m}\right) P_{m i} M_{i}
$$

where $P_{m i} M_{i}$ is total absorption of manufactures in country $i$ and $\frac{w_{i} L_{i}}{1-\alpha}$ is the nominal GDP. We use a standard method of moments estimator to back out $\nu_{c}$ from equation (7).

Given the value of $\phi_{x}$ and the relation $\phi_{x}=\frac{\delta \alpha}{\frac{1}{\beta}-(1-\delta)}$, the depreciation rate for capital is $\delta=0.06$.

\subsection{Country-specific parameters}

We set the workforce, $L_{i}$, equal to the population in country $i$ documented in PWT 8.1. The remaining parameters $A_{c i}, T_{m i}, A_{x i}$, and $d_{i j}$, for $(i, j)=1, \ldots, I$, are not directly observable. We back these out by linking structural relationships of the model to observables in the data.

The equilibrium structure relates the unobserved trade frictions for any two countries directly to the ratio of intermediate goods prices in the two countries and the trade shares between them:

$$
\frac{\pi_{i j}}{\pi_{j j}}=\left(\frac{P_{m j}}{P_{m i}}\right)^{-\theta} d_{i j}^{-\theta} .
$$

Appendix $\mathrm{B}$ describes how we construct the empirical counterparts to prices and trade shares. For observations in which $\pi_{i j}=0$, we set $d_{i j}=10^{8}$. We also set $d_{i j}=1$ if the inferred value of trade cost is less than 1.

Lastly, we use three structural relationships to pin down the productivity parameters 
$A_{c i}, T_{m i}$, and $A_{x i}$ :

$$
\begin{aligned}
\frac{P_{c i} / P_{m i}}{P_{c U} / P_{m U}}=\left(\frac{\left(\frac{T_{m i}}{\pi_{i i}}\right)^{\frac{1}{\theta}} / A_{c i}}{\left(\frac{T_{m U}}{\pi_{U U}}\right)^{\frac{1}{\theta}} / A_{c U}}\right)\left(\frac{\left(\frac{T_{m i}}{\pi_{i i}}\right)^{\frac{1}{\theta}}}{\left(\frac{T_{m U}}{\pi_{U U}}\right)^{\frac{1}{\theta}}}\right)^{\frac{\nu_{c}-\nu_{m}}{\nu_{m}}} \\
\frac{P_{x i} / P_{m i}}{P_{x U} / P_{m U}}=\left(\frac{\left(\frac{T_{m i}}{\pi_{i i}}\right)^{\frac{1}{\theta}} / A_{x i}}{\left(\frac{T_{m U}}{\pi_{U U}}\right)^{\frac{1}{\theta}} / A_{x U}}\right)\left(\frac{\left(\frac{T_{m i}}{\pi_{i i}}\right)^{\frac{1}{\theta}}}{\left(\frac{T_{m U}}{\pi_{U U}}\right)^{\frac{1}{\theta}}}\right)^{\frac{\nu_{x}-\nu_{m}}{\nu_{m}}} \\
\frac{y_{i}}{y_{U}}=\left(\frac{A_{c i}}{A_{c U}}\right)\left(\frac{A_{x i}}{A_{x U}}\right)^{\frac{\alpha}{1-\alpha}}\left(\frac{\left(\frac{T_{m i}}{\pi_{i i}}\right)^{\frac{1}{\theta}}}{\left(\frac{T_{m U}}{\pi_{U U}}\right)^{\frac{1}{\theta}}}\right)^{\frac{1-\nu_{c}+\frac{\alpha}{1-\alpha}\left(1-\nu_{x}\right)}{\nu_{m}}}
\end{aligned}
$$

Equations (9)-(11) are derived in Appendix D. The three equations relate observablesthe price of consumption relative to intermediates, the price of investment relative to intermediates, income per capita, and home trade shares - to the unknown productivity parameters. We set $A_{c U}=T_{m U}=A_{x U}=1$ as a normalization, where the subscript $U$ denotes the United States. For each country $i$, system (9)-(11) yields three nonlinear equations with three unknowns: $A_{c i}, T_{m i}$, and $A_{x i}$. Information about constructing the empirical counterparts to $P_{c i}, P_{m i}, P_{x i}, \pi_{i i}$ and $y_{i}$ is in Appendix B.

These equations are quite intuitive. The expression for income per capita provides a measure of aggregate productivity across all sectors: Higher income per capita is associated with higher productivity levels, on average. The expressions for relative prices boil down to two components. The first term reflects something akin to the Balassa-Samuelson effect: All else equal, a higher price of capital relative to intermediates suggests a low productivity in capital goods relative to intermediate goods. In our setup, the measured productivity for intermediates is endogenous, reflecting the degree of specialization as captured by the home trade share. The second term reflects the relative intensity of intermediate inputs. If measured productivity is high in intermediates, then the price of intermediates is relatively low and the sector that uses intermediates more intensively will have a lower relative price.

\subsection{Model fit}

Our model consists of 8,832 country-specific parameters: $I(I-1)=8,556$ bilateral trade frictions, $(I-1)=92$ consumption-good productivity terms, $(I-1)=92$ investment-good 
productivity terms, and $(I-1)=92$ intermediate-goods productivity terms.

Calibration of the country-specific parameters uses 8,924 data points. The trade frictions use up $I(I-1)=8,556$ data points for bilateral trade shares and $(I-1)=92$ for the ratio of absolute prices of intermediates. The productivity parameters use up $(I-1)=92$ data points for the price of consumption relative to intermediates, $(I-1)=92$ data points for the price of investment relative to intermediates, and $(I-1)=92$ data points for income per capita.

The model matches the targeted data well. The correlation between model and data is 0.96 for the bilateral trade shares (see Figure 1), 0.97 for the absolute price of intermediates, 1.00 for income per capita, 0.96 for the price of consumption relative to intermediates, and 0.99 for the price of investment relative to intermediates.

Figure 1: Model fit for the bilateral trade share - vertical axis, model and horizontal axis, data

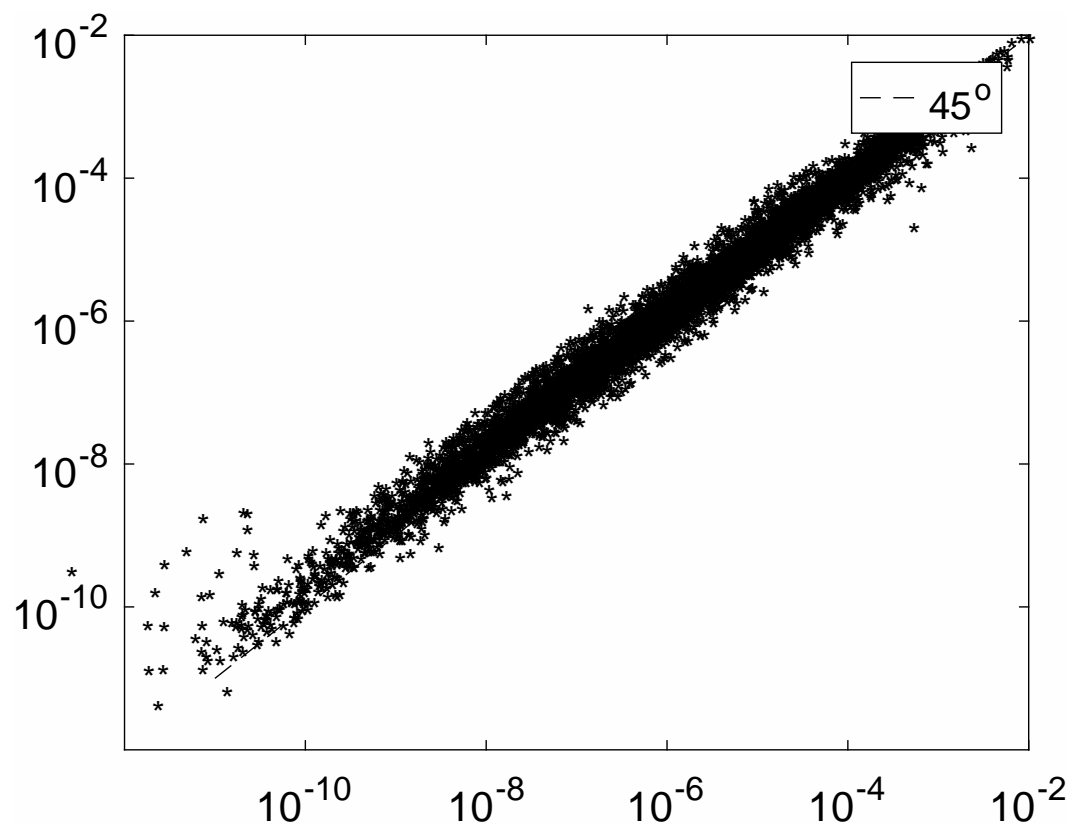

Since we use relative prices of consumption and investment in our calibration, matching the absolute prices is a test of the model (there are more data points than parameters in our calibration). The correlation between the model and the data is 0.93 for the absolute price of consumption and 0.97 for the absolute price of investment.

Our theory has implications also for the (untargeted) cross-country differences in capital and investment rates. Figure 2 shows that the model matches the data on capital-labor ratios 
Figure 2: Model fit—vertical axis, model and horizontal axis, data

(a) Capital-labor ratio

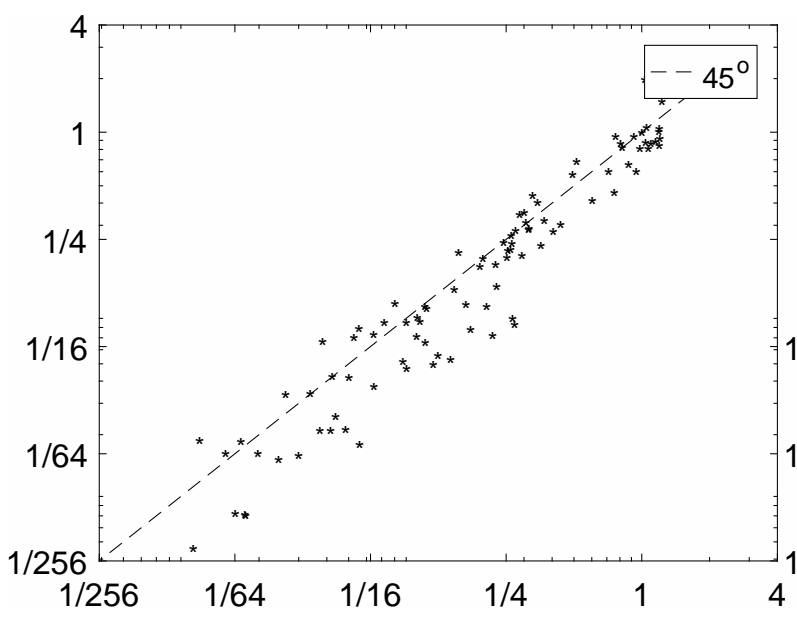

(b) Investment rate

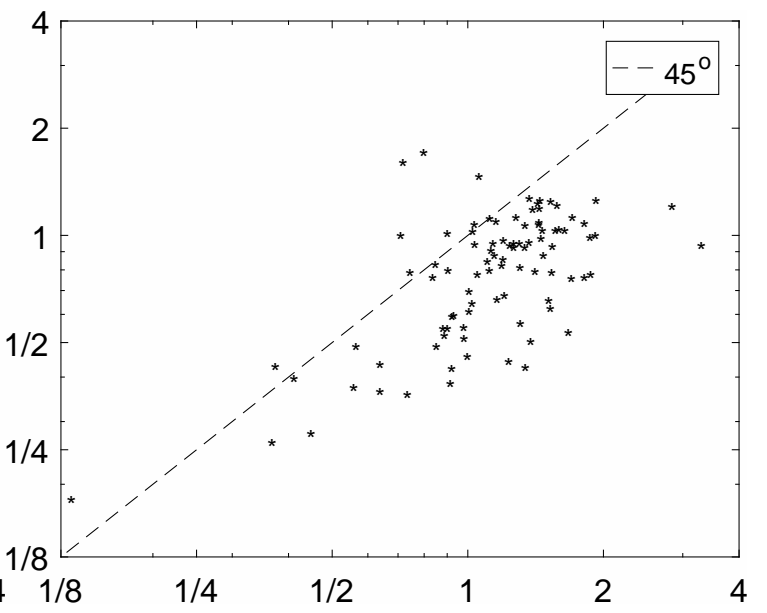

across countries; the correlation is 0.93 . It also shows that our model is broadly consistent with the real investment rate, $\frac{X}{y L}$, across countries.

\section{Counterfactuals}

In this section, we implement a counterfactual trade liberalization via a one-time, unanticipated, uniform, and permanent reduction in trade frictions. The world begins in the calibrated steady state. At the beginning of period $t=1$, trade frictions fall uniformly in all countries such that the ratio of world trade to GDP increases from 50 percent in the calibrated steady state to 100 percent in the new steady state. This amounts to reducing $d_{i j}-1$ by 55 percent for each country pair $i, j$. All other parameters are held fixed at their calibrated values.

Appendix C describes our algorithm for computing the transition path in the counterfactual. Broadly speaking, we first reduce the infinite dimension of the problem down to a finite time model with $t=1, \ldots, T$ periods and use excess-demand iteration. We make $T$ sufficiently large to ensure convergence to a new steady state. This requires us to first solve for a terminal steady state to use as a boundary condition for the path of capital stocks. The other boundary condition is the set of capital stocks in the calibrated steady state; the transition path starts from this set. We guess the entire sequence of wages and rental 
rates in every country. Given the wages and rental rates, we recover all remaining prices and trade shares using optimality conditions for firms, then solve for the optimal sequence of consumption and investment in every country using the intertemporal Euler equation. Finally, we use deviations from domestic market clearing and trade balance conditions to update the sequences of wages and rental rates. We continue the process until we reach a fixed point where all markets clear in all periods.

\subsection{Welfare gains from trade}

We compute the steady-state gains from trade using equation (1) and the dynamic gains from trade using equation $(2) 3^{3}$

Steady-state gains The steady-state gains vary substantially across countries, ranging from 18 percent for the United States to 92 percent for Belize (Figure 3a). The median gain (Greece) is 53 percent.

Recall that consumption is proportional to income in steady state, so in equation (1) consumption can be replaced by income and the welfare gain can be measured by change in per capita income. Steady-state income per capita in country $i$ can be expressed as

$$
y_{i} \propto \underbrace{A_{c i}\left(\frac{T_{m i}}{\pi_{i i}}\right)^{\frac{1-\nu_{c}}{\theta \nu_{m}}}}_{\text {TFP contribution Capital contribution }} \underbrace{A_{x i}^{\frac{\alpha}{1-\alpha}}\left(\frac{T_{m i}}{\pi_{i i}}\right)^{\frac{\alpha\left(1-\nu_{x}\right)}{(1-\alpha) \theta \nu m}}}_{\text {Cii }} .
$$

(See Appendix D for the derivation.) In equation $(12), \pi_{i i}$ in the calibrated steady state is the observed home trade share and $\pi_{i i}$ in the counterfactual steady state with lower trade frictions is computed by solving the dynamic model. All changes in income per capita in (12) are manifested in changes in the home trade share as in ACR. In our model, the ACR formula has to be modified to account for the fact that capital is endogenous and depends on trade frictions; the modification is similar to Mutreja, Ravikumar, and Sposi (2014) and Anderson, Larch, and Yotov (2015).

Equation (12) allows us to decompose the relative importance of changes in TFP and changes in capital in accounting for the steady-state welfare gains. The log-change in welfare

\footnotetext{
${ }^{3}$ We calculate sums in (2) using the counterfactual transition path from $t=1, \ldots, 150$ and setting the counterfactual consumption equal to the new steady-state level of consumption for $t=151, \ldots, 400$.
} 
that corresponds to a log-change in the home trade share is

$$
\frac{\partial \ln \left(y_{i}\right)}{\partial \ln \left(\pi_{i i}\right)}=-(\underbrace{\frac{1-\nu_{c}}{\theta \nu_{m}}}_{\text {through TFP }}+\underbrace{\frac{\alpha\left(1-\nu_{x}\right)}{(1-\alpha) \theta \nu_{m}}}_{\text {through capital }}) .
$$

Based on our calibration, the first term equals 0.08 , while the second term equals 0.30 . That is, 79 percent of the change in income per capita across steady states can be attributed to change in capital and the remaining 21 percent to change in TFP. This decomposition is constant across countries in our model since the elasticities $\left(\theta, \alpha, \nu_{c}, \nu_{m}, \nu_{x}\right)$ are all constant across countries. This does not imply that the change in income is the same across countries (see Figure 3a), only that the relative contributions from TFP and capital are the same.

Figure 3: Distribution of the gains from trade

(a) Gains from trade

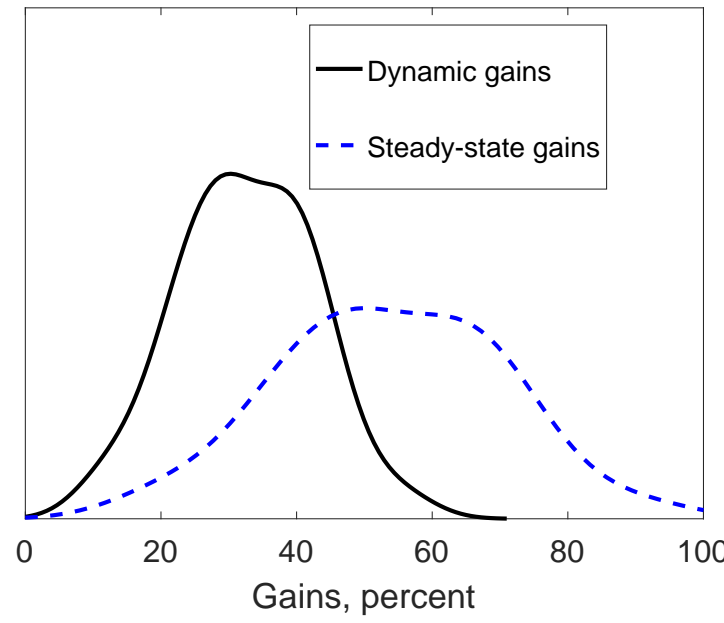

(b) Ratio: dynamic-to-steady-state gains

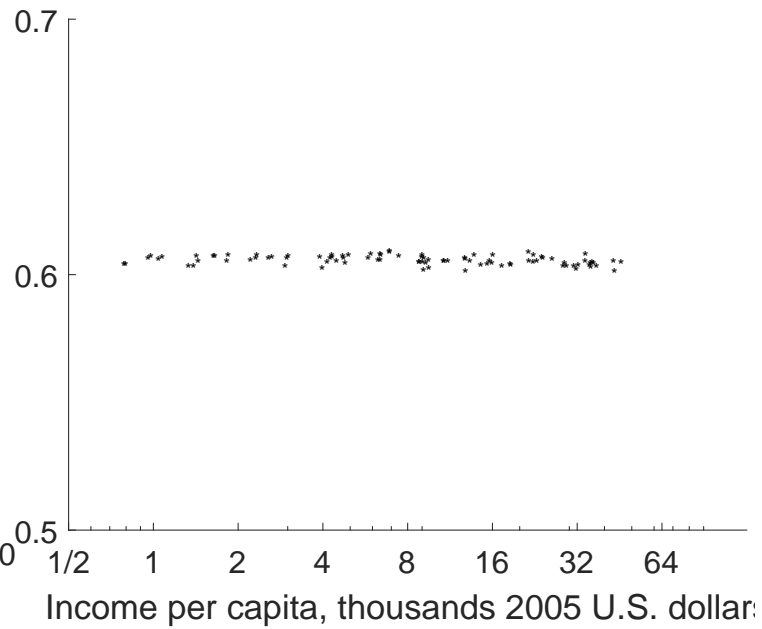

Dynamic gains Dynamic gains also vary substantially across countries, ranging from 11 percent for the United States, to 56 percent for Belize, with the median country (Greece) being 32 percent (Figure 3a). The gains are systematically smaller for large, developed countries, and countries with smaller export frictions. All of these findings are consistent with the existing literature (Waugh and Ravikumar, 2016; Waugh, 2010). Furthermore, the magnitude of our changes in welfare is similar to that in Desmet, Nagy, and Rossi-Hansberg 
(2015) who consider a counterfactual increase of 40 percent in trade costs in a model of migration and trade, and find that welfare decreases by around 34 percent.

Figure $3 \mathrm{a}$ shows that the dynamic gains are smaller. The average ratio of dynamic gains to steady-state gains is 60.2 percent and varies from a minimum of 60.1 percent to a maximum of 60.5 percent (see Figure 3b). This result is not specific to the magnitude of the trade liberalization: The ratio of dynamic to steady-state gains is about 60 percent in every counterfactual where trade frictions are uniformly reduced across countries.

The ratio of roughly 60 percent is a result of (i) the initial change in consumption and (ii) the rate at which consumption converges to the new steady state. If consumption jumped to its new steady-state level on impact, then the ratio would be close to 100 percent. If instead consumption declined significantly in the beginning and then converged to the new steady state slowly, then the ratio would be closer to 0 percent since there would be consumption losses in earlier periods, while higher levels of future consumption would be discounted.

Mechanics The Euler equation (4) reveals the forces that influence consumption dynamics. Trade liberalization increases each country's output, making more resources available for both consumption and investment. The immediate increase in output is driven entirely by an immediate increase in TFP; capital does not change on impact. After the initial increase in output, the allocation to consumption and investment is determined optimally by the household and is governed by two forces: relative price of investment and the return to capital.

Figure 4 shows the transition paths for the relative price of investment and the return to capital for the country with the median gain. The transition paths for other countries are similar, but differ in their magnitudes: Belize is at one extreme and the United States is at the other.

The relative price differences across countries are large in our calibrated steady state and in the data: The relative price in Belize is more than twice that in the U.S. Trade liberalization reduces these price differences: The relative price in Belize is only 10 percent higher than that in the U.S. The decline in the relative price of investment implies the household can increase investment by a larger proportion than the increase in output without giving up consumption. The reason for the decline in the relative price of investment is that trade liberalization decreases the price of traded intermediates and since intermediates are used more intensively in the production of investment goods than in consumption goods 
$\left(\nu_{x}<\nu_{c}\right)$, the price of investment goods falls relative to that of consumption goods $4^{4}$

Figure 4: Transition paths for prices in the median country

(a) Relative price of investment

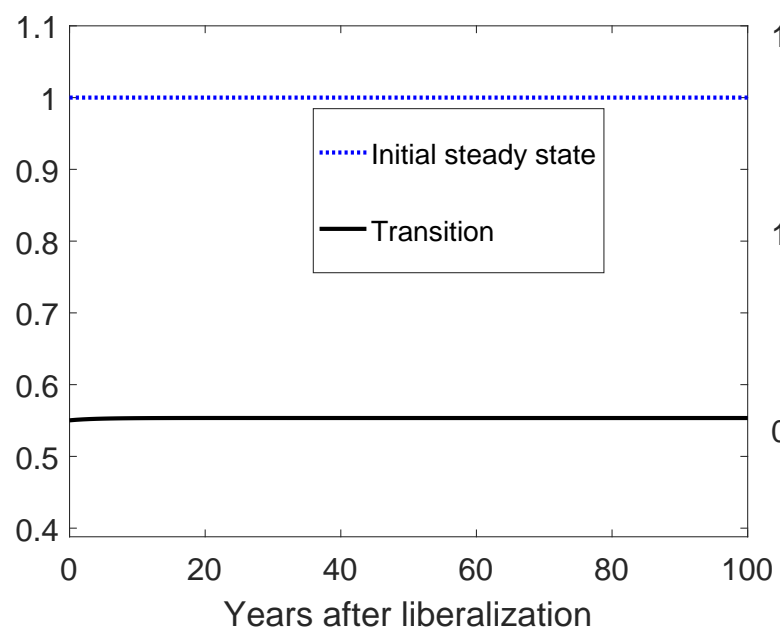

(b) Real rate of return

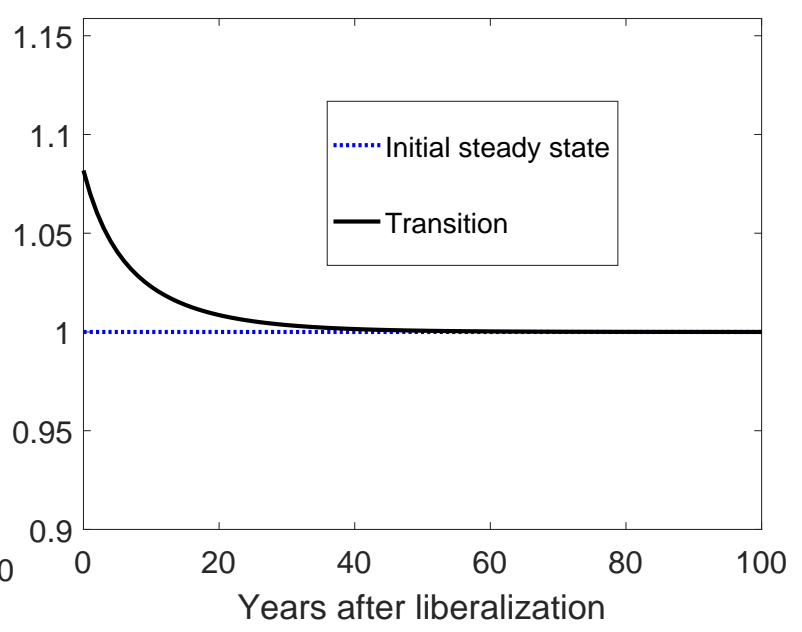

Notes: The country with the median dynamic gain is Greece. Variables are indexed to 1 in the initial steady state.

The return to capital on the transition path, $\left(1+\frac{r_{i t+1}}{P_{x i t+1}}-\delta\right)$, is higher than the steadystate return, $\frac{1}{\beta}$. This is because, following the trade liberalization, measured TFP is higher. With the higher return, households invest more. As a result of the increased investment the capital-labor ratio increases along the transition, which eventually drives the return back to its initial steady-state level. As capital accumulates, output increases. Recall that the increase in output on impact is entirely due to TFP, whereas the increase in output after the initial period is driven entirely by capital accumulation. With higher output, both consumption and investment increase and settle to the new, higher steady-state levels.

Relation to static models The dynamic gains from trade are quantitatively higher than those in a model where factors of production are held fixed. In a static model, the gains from trade are driven entirely by changes in TFP. In our dynamic model, TFP jumps immediately to (almost) its new steady-state level (see Figure 5) and the change in TFP is

\footnotetext{
${ }^{4}$ Using input-output data for 40 countries we find that there is indeed variation in $\nu_{c}$ and $\nu_{x}$. In every one of these countries $\nu_{x}-\nu_{c}<0$, with a range from -0.35 to -0.71 . However, we assume that both $\nu_{c}$ and $\nu_{x}$ are constant across countries since (i) we do not have data on these shares for our sample of 93 countries and (ii) country-specific values for these parameters add noise to the channels that we explore. We should note that allowing for these shares to differ across countries is straightforward with our solution algorithm.
} 
exactly the same as that in a static model. Based on our decomposition in equation (12), the static gains are 21 percent of the steady-state gains. We also know from our counterfactual exercise that the dynamic gains are around 60 percent of the steady-state gains. Therefore, the dynamic gains are almost three times as large as the static gains.

Figure 5: Transition path for TFP in the median country

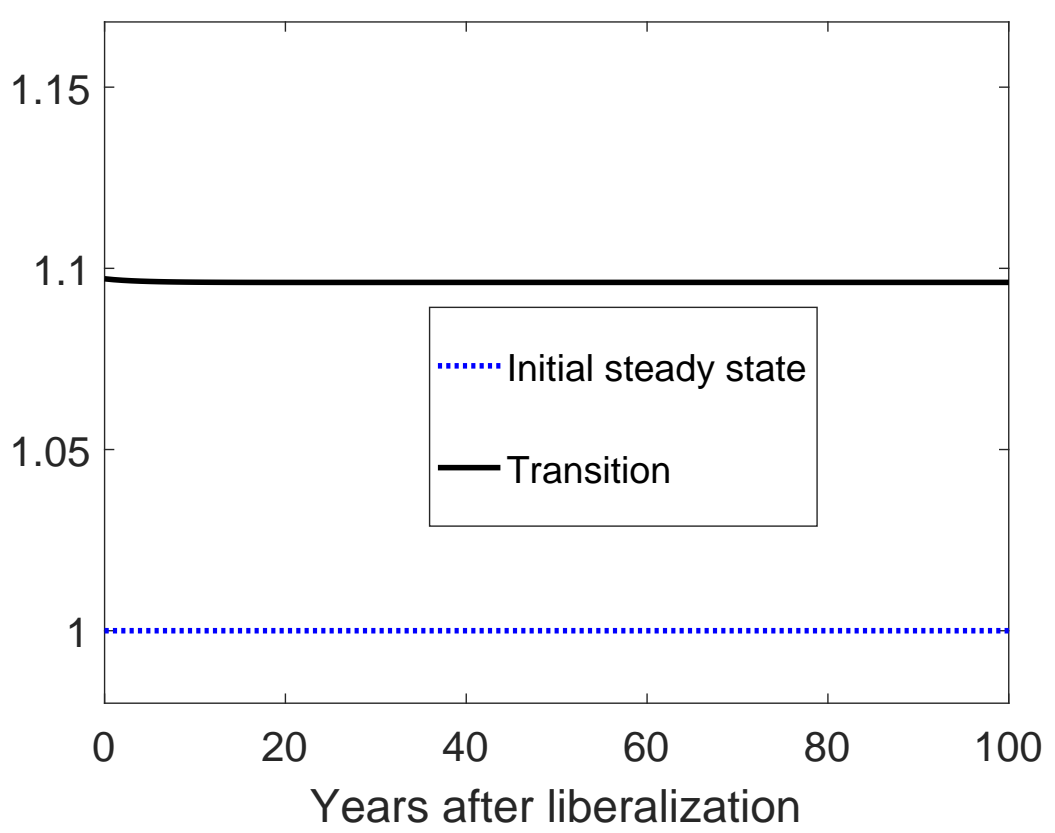

Notes: The country with the median dynamic gain is Greece. TFP is indexed to 1 in the initial steady state.

\subsection{Role of investment rate and relative price of investment}

In this section, we examine the importance of the two channels in our model: the endogenous relative price of investment and the endogenous investment rate. To quantify their importance, we solve versions of the model where we fix the nominal investment rate and the relative price of investment. To do this, we change a few equations and recalibrate the model to match the same target moments as in the benchmark calibration.

Fixed nominal investment rate To impose a fixed nominal investment rate, we eliminate the intertemporal Euler equation (4) and set $P_{x i t} X_{i t}=\rho\left(w_{i t} L_{i t}+r_{i t} K_{i t}\right)$, with $\rho=\frac{\alpha \delta}{1 / \beta-(1-\delta)}=0.1948$. That is, the nominal investment rate, $\rho$, is the value in the calibrated 
steady state and is the same across countries. But we allow for the relative price of investment to change in the counterfactual. With the fixed nominal investment rate, the household's budget constraint becomes

$$
P_{c i t} C_{i t}=(1-\rho)\left(r_{i t} K_{i t}+w_{i t} L_{i}\right)
$$

We implement a similar trade liberalization in which frictions are uniformly reduced by 55 percent in every country. With a fixed investment rate, there is no need to solve the intertemporal Euler equation so the method for computing the counterfactual transition path is straightforward. We do not need to iterate on an entire sequence of wages and rental rates. Instead, we solve a sequence of static problems where in each period we iterate on wages at that point in time. In the first period, we start with the calibrated steadystate capital distribution and solve for the wages in period 1. The household allocates a fixed share of its period-1 income to investment expenditures, which determines the capital stock at $t=2$. In the second period, we start with that capital stock, solve another static problem, and determine the capital stock for $t=3$. Repeating this sequence generates the entire transition path. Note that in this calculation future wages or rental rates (or trade frictions) have no impact on current allocations whereas in our model the current allocations depend on the entire sequence of wages and rental rates.

Figure 6a illustrates the dynamic gains for the case where the nominal investment rate is fixed and for the case where it responds to the reduction in trade frictions. The gains in the two cases are practically identical. However, the manner in which the two gains are realized is different. In the fixed nominal investment rate case, consumption increases on impact and converges to the new steady state slowly whereas in the case of endogenous investment rate, consumption decreases on impact but converges to the steady state rapidly; see Figure 6b. (In both cases, the counterfactual steady state is the same.) This difference in the consumption paths manifests itself in the rates of capital accumulation in the two cases. In our model, all countries experience an increase in nominal investment rate on impact, from 19.5 percent to a range of 24 to 35 percent. Half-life - the time taken to close half the gap between the calibrated and counterfactual steady states - in the fixed investment rate case is twice as large as that in the endogenous investment rate case.

Fixed nominal investment rate and relative price of investment In addition to a fixed nominal investment rate, we fix the relative price of investment, $\frac{P_{x i t}}{P_{c i t}}$, to 1 . To do this, we restrict the technologies for consumption and investment goods to be the same. That 
Figure 6: Dynamic gains across countries and consumption dynamics for the median country

(a) Dynamic gains

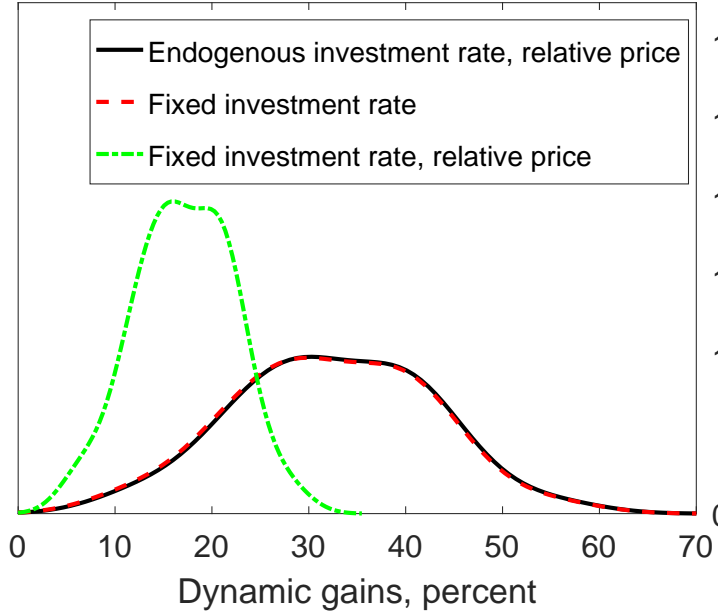

(b) Consumption dynamics for the median country

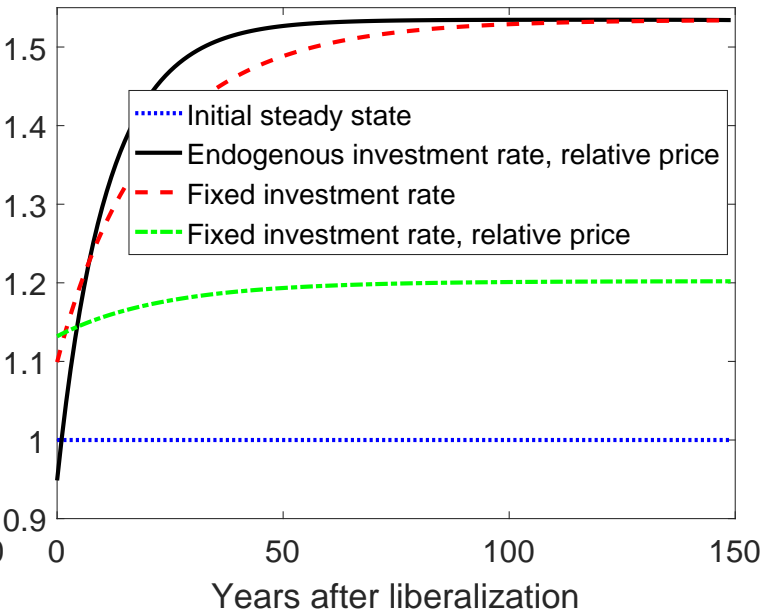

Notes: The country with the median dynamic gain is Greece. Consumption is indexed to 1 in the initial steady state.

is, we set $A_{x i}=A_{c i}$ for every $i$ (but allow for variation across countries) and set $\nu_{x}=\nu_{c}$. We choose $A_{x i}=A_{c i}$ to match the price of GDP relative to intermediates in country $i$ and choose $\nu_{x}=\nu_{c}=0.88$ to satisfy the national income accounts equation (7). We recalibrate all other parameters to match the same targets as in the benchmark calibration.

Again, we implement a similar trade liberalization in which frictions are uniformly reduced by 55 percent. The dynamic gains with fixed nominal investment rate and relative price of investment are lower for every country compared to the case where the investment rate and the relative price respond to changes in trade frictions (see Figure 6a). The median dynamic gain in the latter case is 1.9 times as large. Figure $6 \mathrm{~b}$ shows that consumption increases on impact in the former case and converges gradually to the new steady state. In the latter case, consumption decreases on impact and converges rapidly to the new steady state. Steady-state consumption, however, in the latter case is higher. With an endogenous relative price, the real investment rate converges to a higher steady-state level (81 percent higher for the median-gain country) since the opportunity cost of investing - the amount of consumption goods the household gives up to acquire additional investment - is lower. This implies a higher capital stock and higher output in steady state and, hence, higher consumption.

Our model implies that the median steady-state gain is 2.6 times as large as that in a 
model with a fixed nominal investment rate and a fixed relative price of investment. Furthermore, the contribution of capital is relatively less important in the case with the fixed investment rate and relative price: It accounts for only 33 percent of the steady-state gains compared with 79 percent with the endogenous investment rate and relative price. The lower contribution of capital in the fixed relative price and investment rate case implies that most of the gains are due to TFP, which happens on impact. Hence, the ratio of dynamic gains to steady-state gains is larger in this case ( 82 percent) than in our model (60 percent).

In sum, an endogenous investment rate implies smaller short-run gains but a faster transition to the steady state, while an endogenous relative price implies a higher steady state.

\subsection{Comparison with the sufficient statistics approach}

In the steady state in our model, using equation (12), the change in welfare for country $i$ is given by

$$
\hat{y}_{i} \propto \underbrace{\left(\hat{\pi}_{i i}\right)^{-\frac{1-\nu_{c}}{\theta \nu_{m}}}}_{\text {TFP contribution Capital contribution }} \underbrace{\left(\hat{\pi}_{i i}\right)^{-\frac{\alpha\left(1-\nu_{x}\right)}{(1-\alpha) \theta \nu_{m}}}},
$$

where the hat denotes the ratio of the variable's value in the counterfactual steady state to its value in the initial steady state. Equation (14) implies that the change in country $i$ 's home trade share is sufficient to pin down the change in country $i$ 's welfare across steady states.

Equation (14) is similar to the sufficient statistic formula used by ACR except we have an additional term that accounts for the change in capital. As in ACR, computing the welfare cost of moving to autarky is straightforward since the home trade share in the initial steady state is the observed home trade share and the home trade share under autarky is 1 . Thus, there is no need to solve the model for the counterfactual home trade share and the observed home trade share is sufficient to describe the steady-state welfare cost of autarky.

Computing the gains from moving to a frictionless trade world requires computing the counterfactual value of the home trade. In a static model, Waugh and Ravikumar (2016) provide a sufficient statistics formula that describes the gains. In their formula, cross-country observations on home trade shares and income are sufficient to compute the welfare gains.

Aside from the extreme cases of autarky and frictionless trade, computing changes in welfare across steady states involves solving the entire model for each counterfactual reduction in trade frictions.

In our dynamic model, computing the welfare gain along the transition path by applying 
equation (14) period by period is invalid. First, along the transition, consumption is not proportional to income. For instance, consumption in the median-gain country grows by 4.7 percent between periods 2 and 3, while income grows by only 3.4 percent. Second, even if consumption was roughly proportional to income, changes in the home trade share between any two periods does not describe changes in income.

Figure 7 plots the transition path for the home trade share, consumption and income in our model for the median-gain country. The home trade share jumps on impact to the new steady state level and remains constant thereafter (see Figure 7a). Income growth, however, remains above 1 percent even after 12 periods (see Figure $7 \mathrm{~b}$ ).

Figure 7: Transition path for the home trade share in the median country

(a) Home trade share

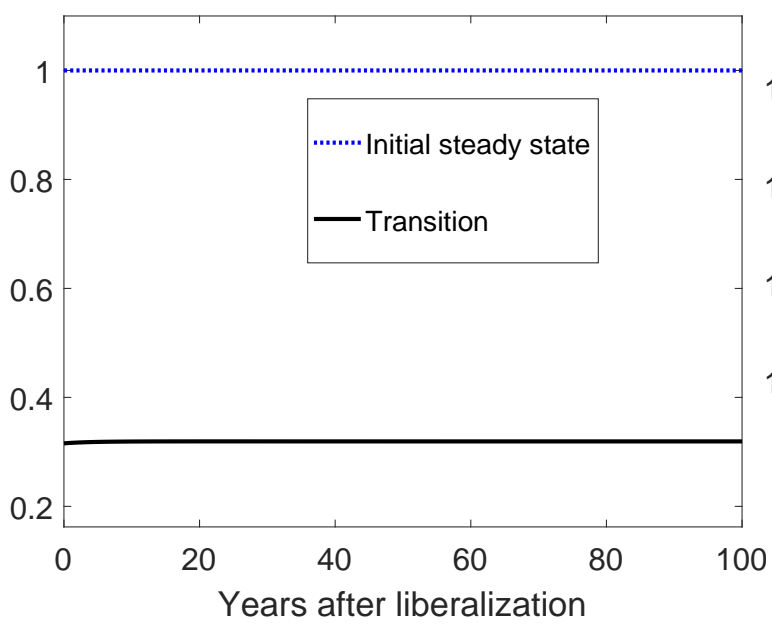

(b) Consumption and income

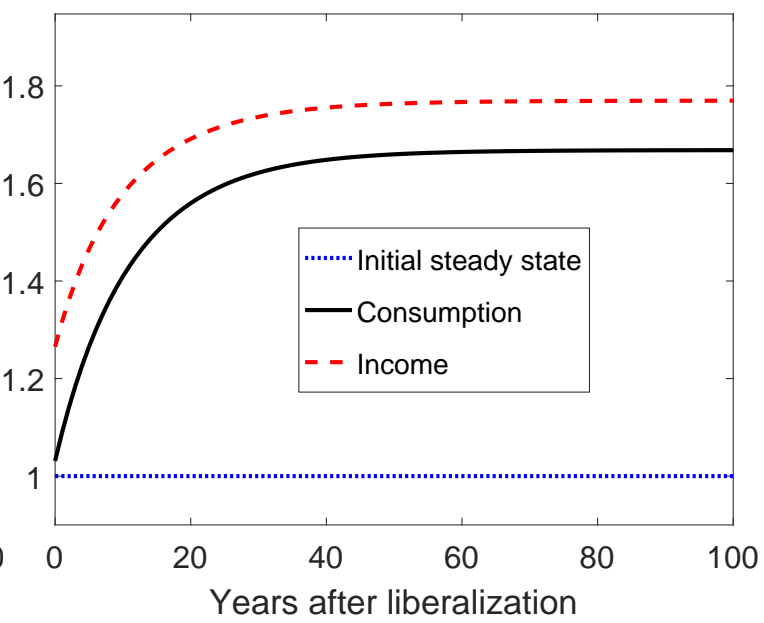

Notes: The country with the median dynamic gain is Greece. Variables are indexed to 1 in the initial steady state.

Furthermore, even in the autarky and frictionless trade counterfactuals, changes in income occur over the course of many periods, whereas the sufficient statistics formula would imply that all of the changes occur on impact.

\section{Trade imbalances}

In our model with balanced trade households cannot borrow from or lend to other countries. The welfare gains from trade reported in Section 4 could thus be an underestimate. 
We introduce trade imbalances by allowing each country to buy and sell one-period bonds. The bonds yield a risk-free world interest rate $q_{t}$ in period $t$. The household's budget constraint becomes

$$
P_{c i t} C_{i t}+P_{x i t} X_{i t}+B_{i t}=w_{i t} L_{i t}+r_{i t} K_{i t}+q_{t} \mathcal{A}_{i t}
$$

where $B_{i t}$ denotes net purchases of one-period bonds or the current account balance and $\mathcal{A}_{i t}$ denotes the net foreign asset (NFA) position. NFAs accumulate according to

$$
\mathcal{A}_{i t+1}=\mathcal{A}_{i t}+B_{i t}
$$

We also introduce adjustment costs to capital accumulation as in Eaton, Kortum, Neiman, and Romalis (2016). In equilibrium, the real rates of return on bonds and investment are equalized. Without adjustment costs, the household's choice of bonds and investment goods is indeterminate. With an adjustment cost to capital accumulation, the household's chooses a unique portfolio. We specify the adjustment costs as follows:

$$
K_{i t+1}=(1-\delta) K_{i t}+\chi X_{i t}^{\mu} K_{i t}^{1-\mu}
$$

where $\chi$ denotes the efficiency of investment and $\mu$ governs the adjustment cost. For convenience, we work with investment:

$$
X_{i t}=\Phi\left(K_{i t+1}, K_{i t}\right)=\left(\frac{1}{\chi}\right)^{\frac{1}{\mu}}\left(K_{i t+1}-(1-\delta) K_{i t}\right)^{\frac{1}{\mu}} K_{i t}^{\frac{\mu-1}{\mu}}
$$

This technology implies that from each household's perspective, the rate of return on investment depends on the quantity of investment.

The dynamics are now governed by two intertemporal Euler equations:

$$
\frac{C_{i t+1}}{C_{i t}}=\beta^{\sigma}\left(\frac{1+q_{t+1}}{P_{c i t+1} / P_{c i t}}\right)^{\sigma}
$$

and

$$
\frac{C_{i t+1}}{C_{i t}}=\beta^{\sigma}\left(\frac{\frac{r_{i t+1}}{P_{i x t+1}}-\Phi_{2}\left(K_{i t+2}, K_{i t+1}\right)}{\Phi_{1}\left(K_{i t+1}, K_{i t}\right)}\right)^{\sigma}\left(\frac{P_{x i t+1} / P_{c i t+1}}{P_{x i t} / P_{c i t}}\right)^{\sigma},
$$

where $\Phi_{1}(\cdot, \cdot)$ and $\Phi_{2}(\cdot, \cdot)$ denote the first derivatives of the adjustment-cost function with 
respect to the first and second arguments, respectively:

$$
\begin{aligned}
& \Phi_{1}\left(K^{\prime}, K\right)=\left(\frac{1}{\chi}\right)^{\frac{1}{\mu}}\left(\frac{1}{\mu}\right)\left(\frac{K^{\prime}}{K}-(1-\delta)\right)^{\frac{1-\mu}{\mu}} \\
& \Phi_{2}\left(K^{\prime}, K\right)=\left(\frac{1}{\chi}\right)^{\frac{1}{\mu}}\left(\frac{1}{\mu}\right)\left(\frac{K^{\prime}}{K}-(1-\delta)\right)^{\frac{1-\mu}{\mu}}\left((\mu-1) \frac{K^{\prime}}{K}-\mu(1-\delta)\right) .
\end{aligned}
$$

To close the model, we require that the current account balance equals net exports plus net-foreign income on assets in each country:

$$
B_{i t}=P_{m i t}\left(Y_{m i t}-M_{i t}\right)+q_{t} \mathcal{A}_{i t}
$$

\subsection{Quantitative implications with trade imbalances}

We calibrate $\mu=0.55$ as in Eaton, Kortum, Neiman, and Romalis (2016). We set $\chi=$ $\delta^{1-\mu}=0.28$, so that there is no cost to maintain the level of capital stock in steady state, i.e., $X=\delta K$.

We assume that the world is in steady state in 2011 with balanced trade and an initial NFA position: $\mathcal{A}_{i 1}=0$ for all $i$. We calibrate the model to the same targets as in Section 3. We use the steady-state level of capital stock from this calibration as the initial level for capital before trade liberalization. These assumptions help us compare the results in our model with balanced trade.

To implement our algorithm, we impose a value for the terminal NFA position, $\mathcal{A}_{i T+1}$, for all $i$; without loss of generality, we set these to 0 . We let the model run for 150 periods and discard the last 65. By period 85, the model has converged to a steady state that is independent of the terminal NFA positions. This is an application of the turnpike theory: Regardless of the terminal value for $\mathcal{A}_{i T+1}$, if $T$ is large enough, then there is a time $t^{\star}$ at which the model is sufficiently close to the steady state (i.e., on the turnpike). This approach is also used by Kehoe, Ruhl, and Steinberg (2016) 5 5 We describe the algorithm to compute the transitional dynamics in Appendix E.

\footnotetext{
${ }^{5}$ In models with endogenous current accounts, it is known that the transition path and steady state are determined jointly. The new steady state is one in which current accounts are balanced in all countries but have potentially permanent trade imbalances. The steady state depends on the transition path since a country may accumulate assets early on, financed by a trade surplus, but collect income later from the assets and use it to finance a trade deficit. As such, its steady-state trade imbalance depends on what happened along the transition. So NFA positions need not be 0 in steady state. After 85 periods, the NFA position begins to revert to its terminal position.
} 
We compare the results in our model with trade imbalances to those in a model with balanced trade and adjustment costs to capital. That is, we add adjustment costs to our model with balanced trade in Section 2, recalibrate it, and solve it under the counterfactual. This ensures that the only difference between the two models is the presence or lack of trade imbalances.

Welfare gains Figure 8 illustrates the cross-country distribution of steady-state gains and dynamic gains in both models. The dynamic gains are practically the same in both models; the gains differ across countries by a factor of 5 .

Figure 8: Distribution of gains from trade: Balanced trade versus unbalanced trade

(a) Dynamic gains

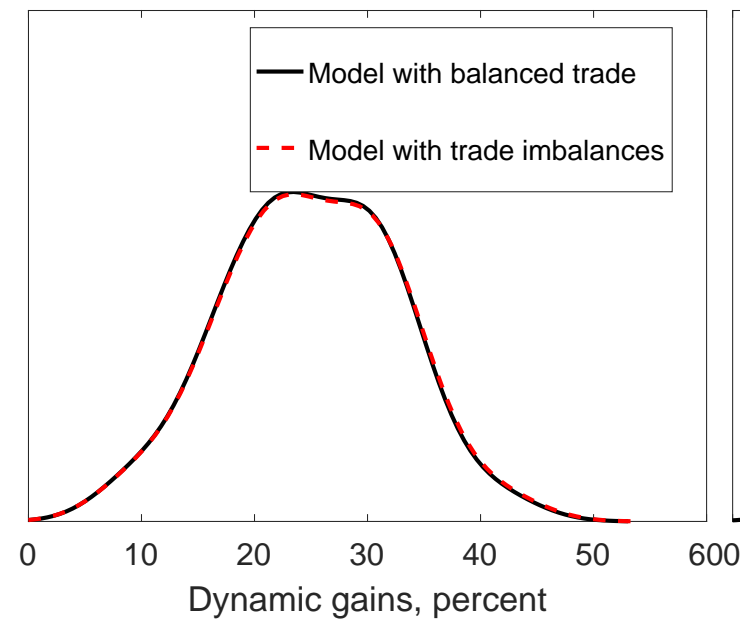

(b) Steady-state gains

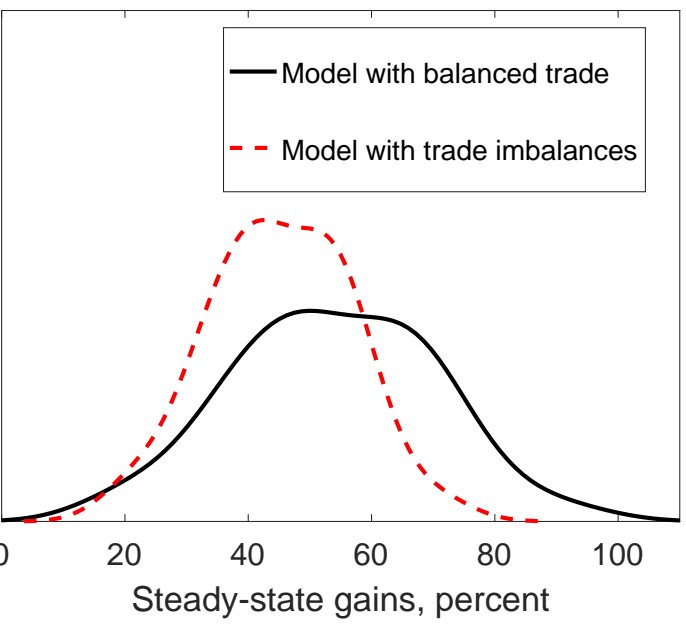

Under balanced trade, the rate at which the gains accrue in each country is the same, but with trade imbalances these rates differ across countries. Small, less-developed countries front-load their consumption by running trade deficits in the short run while large, developed countries do the opposite. Under balanced trade, there are persistent differences in the rates of return along the transition path across countries, ranging from 4 to 7 percent. In the model with trade imbalances, the bond market ensures that the returns are equalized across countries at every point in time. This equalization occurs via financial resources flowing from large, developed countries to small, less-developed countries. Figure 9 illustrates the trade deficits and real rates of return across countries at the time of trade liberalization.

Along the transition, some countries accumulate NFAs by running current account sur- 
Figure 9: Trade imbalances and rates of return in the period of trade liberalization

(a) Ratio of net exports to GDP

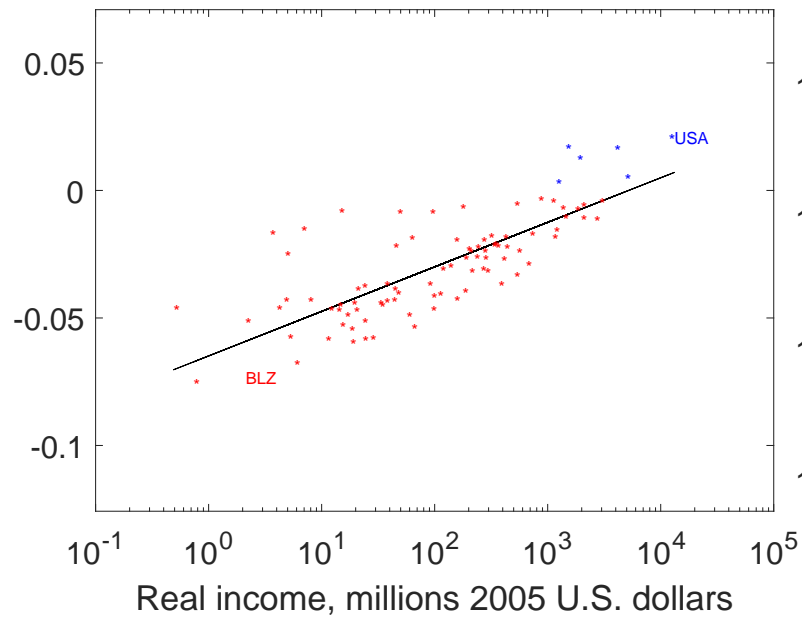

(b) Gross real rate of return

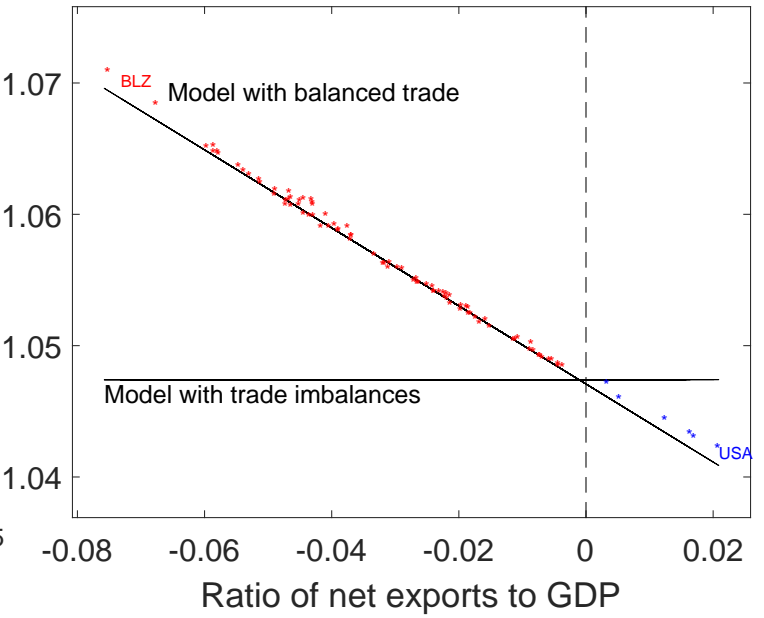

pluses, while others accumulate liabilities by running current account deficits. To illustrate this point, consider the case of the United States and Belize. Following the trade liberalization, the United States runs a current account surplus (see Figure 10). On impact, the current account surplus exactly equals the trade surplus. In the ensuing periods, the trade surplus shrinks faster than the current account surplus, since the United States earns positive net foreign income from its NFA position. In a matter of 14 periods, the U.S. trade is balanced, meaning that net purchases of bonds (its current account balance) exactly offset its net foreign income. After period 14, the United States continues to run a current account surplus, although its net exports turn negative as its net foreign income exceeds its current account surplus. In the new steady state, the current account is balanced and the U.S. runs a permanent trade deficit that is financed by net foreign income that accrues from its permanent and positive NFA position.

The current account dynamics in Belize are the mirror image of those in the United States, where Belize converges to a steady state with permanent net liabilities offset by a permanent trade surplus.

The cross-country distribution of steady-state gains differs from that in the balanced trade model (see Figure 8. Steady-state gains differ by a factor of 3.6 in the model with trade imbalances whereas they differ by a factor of 5 in the balanced trade model. Relative to the balanced trade model, steady-state gains are larger for large, developed countries and smaller 
Figure 10: Transition for current account and net exports in the United States and Belize

(a) Ratio of current account to GDP

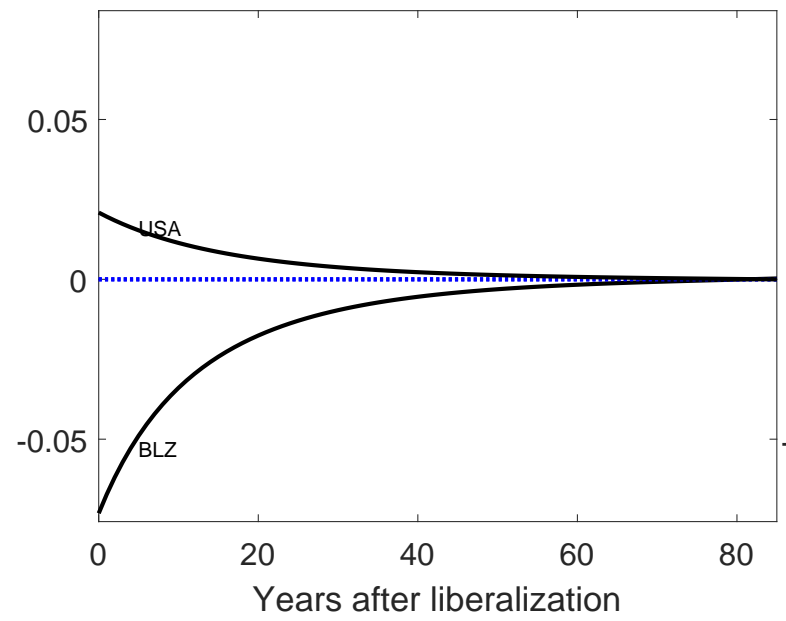

(b) Ratio of net exports to GDP

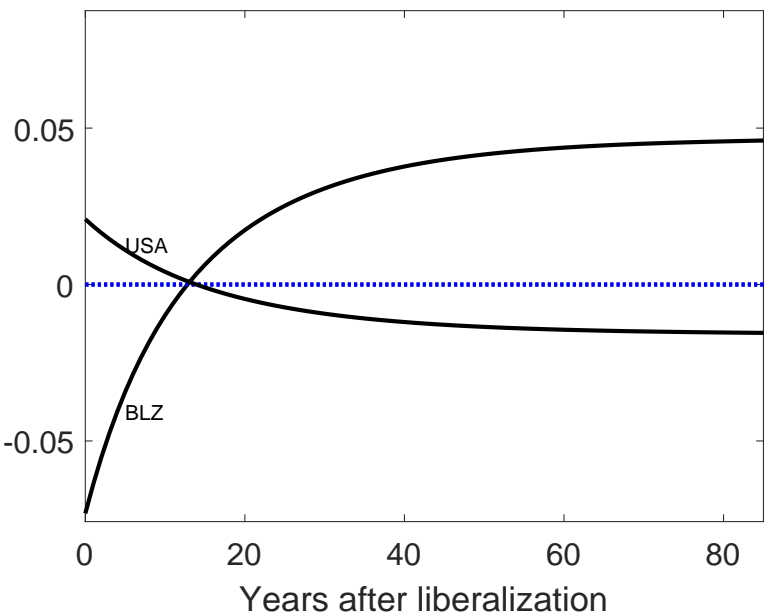

for small, less-developed countries. For instance, the gain across steady states for Belize is 92 percent in the balanced trade model and 71 percent in the model with trade imbalances. Consumption for Belize in the new steady state is less in the model with trade imbalances than in the model with balanced trade since it front-loads consumption by running a trade surplus in the long run. As a result, the steady-state gains for Belize are smaller in the model with trade imbalances. The corresponding steady-state gains for the United States are 18 and 20 percent, respectively. In contrast to the model with balanced trade, the dynamic gain in the model with trade imbalance is not proportional to the steady-state gain.

The behavior of trade imbalances also reveal a pattern in the rates of capital accumulation from the calibrated steady state to the counterfactual steady state. Figure ?? illustrates that the half-life for capital accumulation varies with trade deficits. Countries with trade deficits in the short run have lower half lives than countries with trade surpluses in the short run. Furthermore the relationship is nonlinear: The half life increases exponentially with the size of of the short-run trade surpluses.

The two channels, endogenous relative price of investment and endogenous investment rate, are quantitatively important in the model with trade imbalances as well. The dynamic gains are 37 percent lower when both the relative price of investment and the investment rate are fixed. 
Figure 11: Half-life for capital accumulation

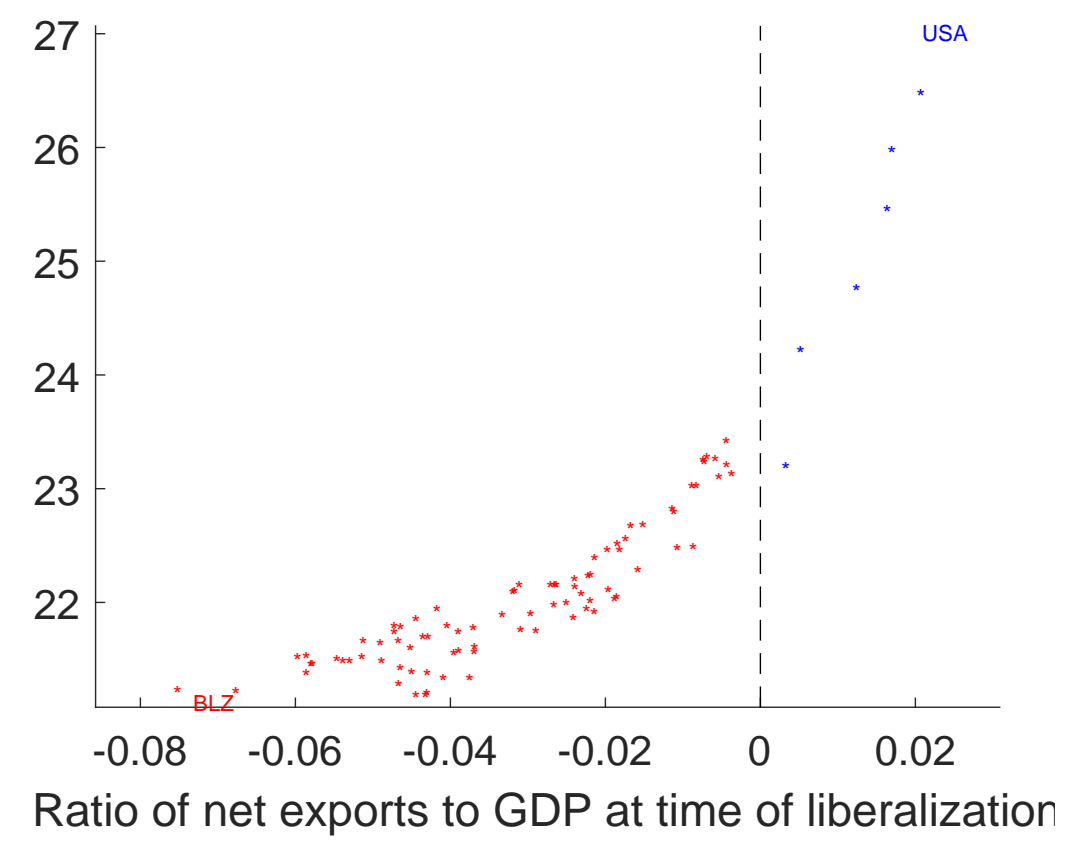

Sufficient statistics Recall from Section 4.3 that our model with balanced trade admits a sufficient statistics formula to compute the welfare gains from trade across steady states, but not in the transition. In the model with trade imbalances, the sufficient statistics formula does not yield welfare gains even across steady states. This is because (i) the change in home trade share does not reflect the change in income and (ii) consumption is not proportional to income in the steady state.

The real income in a country is affected by its steady-state trade imbalance, a phenomenon that is not fully summarized by the home trade share. Given the same drop in home trade share, countries with steady-state trade deficits, such as the United States, have smaller increase in income than countries with steady-state surpluses, such as Belize (see Figure 12]. But since Belize has a trade surplus in the new steady state, its change in income overstates its change in consumption and, hence, its steady-state welfare gain. 
Figure 12: Elasticity of income with respect to home trade share

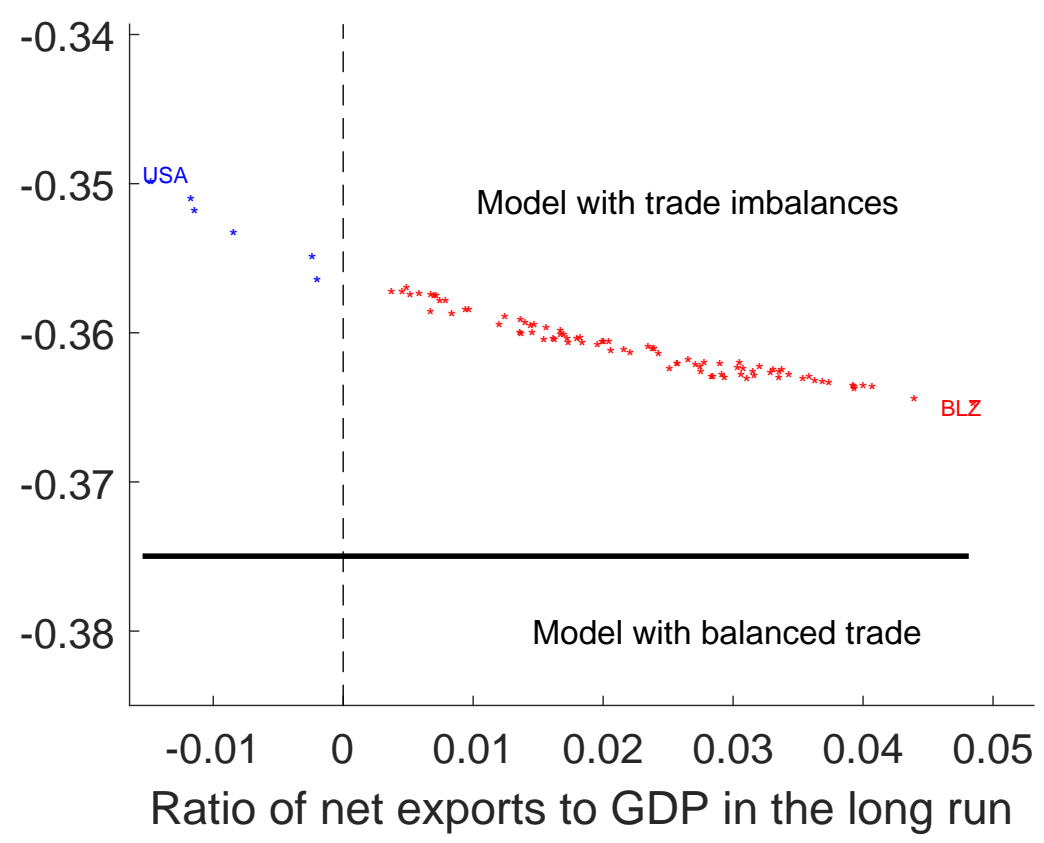

\section{Conclusion}

We build a multicountry trade model with capital accumulation where the relative price of investment and the investment rate are affected by trade frictions. We use this framework to study dynamic welfare gains after a trade liberalization. We develop an algorithm to efficiently solve for the exact transitional dynamics for a system of second-order, nonlinear difference equations. Our counterfactual suggests that the dynamic gains differ by a factor of 5 across countries. The dynamic gains are 60 percent of the steady-state gains and three times as large as static gains. Almost 80 percent of the gains are due to capital accumulation.

Trade liberalization reduces the relative price of investment, allowing countries to invest more without forgoing consumption, and therefore attain permanently higher capital-labor ratios. As a result, output and consumption in the steady state are higher than in a model with a fixed price of investment. Trade liberalization also increases total factor productivity which increases the rate of return to investment. This affects the dynamic path of investment. As capital accumulates, consumption increases and the welfare gains accrue over time. In a model where the relative price of investment and the investment rate do not respond to changes in trade frictions, the dynamic gains are only half as large and capital accumulation 
contributes only a third to the welfare gains.

Finally, we find that the distribution of the dynamic gains in a model with endogenous trade imbalances is almost identical to that in the balanced trade model. However, the rate at which the dynamic gains accrue in each country is different from that in the balanced trade model. Small, less-developed countries front-load consumption, while large, developed countries do the opposite. Hence, the short-run gains for small, less-developed countries are larger than those for large, developed countries.

In the model with balanced trade, changes in home trade share are not sufficient to measure welfare gains along the transition path. In the model with trade imbalances, changes in home trade share are not sufficient to welfare gains even across steady states.

Our solution method can be used to analyze other types of trade liberalizations such as unilateral reduction of trade frictions or a gradual reduction in trade frictions.

\section{References}

Affendy, Arip M., Lau Sim Yee, and Madono Satoru. 2010. "Commodity-industry Classification Proxy: A Correspondence Table Between SITC Revision 2 and ISIC Revision 3." MPRA Paper 27626, University Library of Munich, Germany.

Alessandria, George, Horag Choi, and Kim Ruhl. 2014. "Trade adjustment dynamics and the welfare gains from trade." Working paper, National Bureau of Economic Research.

Alvarez, Fernando and Robert E. Lucas. 2007. "General Equilibrium Analysis of the EatonKortum Model of International Trade." Journal of Monetary Economics 54 (6):1726-1768.

- 2016. "Capital Accumulation and International Trade." Working paper, University of Chicago.

Anderson, James, Mario Larch, and Yoto Yotov. 2015. "Growth and Trade with Frictions: A Structural Estimation Framework." Working Paper 21377, National Bureau of Economic Research.

Arkolakis, Costas, Arnaud Costinot, and Andrés Rodríguez-Clare. 2012. "New Trade Models, Same Old Gains?" American Economic Review 102 (1):94-130.

Baldwin, Richard E. 1992. "Measurable dynamic gains from trade." Journal of Political Economy 100 (1):162-174. 
Bernard, Andrew B., Jonathan Eaton, J. Bradford Jensen, and Samuel Kortum. 2003. "Plants and Productivity in International Trade." American Economic Review $93(4): 1268-1290$.

Brooks, Wyatt J. and Pau S. Pujolas. 2016. "Capital Acumulation and the Welfare Gains from Trade." Working Paper Series 2016-03, McMaster University.

Caliendo, Lorenzo, Maximiliano Dvorkin, and Fernando Parro. 2015. "The Impact of Trade on Labor Market Dynamics." Working Paper 21149, National Bureau of Economic Research.

Desmet, Klaus, Dávid Krisztián Nagy, and Esteban Rossi-Hansberg. 2015. "The Geography of Development: Evaluating Migration Restrictions and Coastal Flooding." Working paper, National Bureau of Economic Research.

Eaton, Jonathan and Samuel Kortum. 2002. "Technology, Geography, and Trade." Econometrica 70 (5):1741-1779.

Eaton, Jonathan, Samuel Kortum, Brent Neiman, and John Romalis. 2016. "Trade and the Global Recession." American Economic Review 106 (11):3401-3438.

Feenstra, Robert C., Robert Inklaar, and Marcel Timmer. 2015. "The Next Generation of the Penn World Table." American Economic Review 105 (10):3150-82.

Gollin, Douglas. 2002. "Getting Income Shares Right." Journal of Political Economy $110(2): 458-474$.

Kehoe, Timothy J., Kim J. Ruhl, and Joseph P. Steinberg. 2016. "Global Imbalances and Structural Change in the United States." NBER Working Papers 19339, National Bureau of Economic Research.

Lucas, Robert E. 1987. Models of business cycles, vol. 26. Basil Blackwell Oxford.

Mutreja, Piyusha, B. Ravikumar, and Michael Sposi. 2014. "Capital Goods Trade and Economic Development." Working Papers 2014-12, Federal Reserve Bank of St. Louis.

Reyes-Heroles, Ricardo. 2016. "The Role of Trade Costs in the Surge of Trade Imbalances." Mimeo, Princeton University. 
Simonovska, Ina and Michael E. Waugh. 2014. "The Elasticity of Trade: Estimates and Evidence." Journal of International Economics 92 (1):34-50.

Sposi, Michael. 2012. "Evolving Comparative Advantage, Structural Change, and the Composition of Trade." Mimeo, University of Iowa.

Waugh, Michael E. 2010. "International Trade and Income Differences." American Economic Review 22 (5):2093-2124.

Waugh, Michael E. and B. Ravikumar. 2016. "Measuring openness to trade." Journal of Economic Dynamics and Control 72:29-41.

Zylkin, Thomas. 2016. "Feeding China's Rise: The Growth Effects of Trading with China, 1993-2011." GPN working paper series, National University of Singapore. 


\section{Appendix}

\section{A Equilibrium conditions in the balanced trade model}

We describe each equilibrium condition in detail below.

Household optimization The representative household chooses a path for consumption that satisfies the following Euler equation:

$$
\frac{C_{i t+1}}{C_{i t}}=\beta^{\sigma}\left(1+\frac{r_{i t+1}}{P_{x i t+1}}-\delta\right)^{\sigma}\left(\frac{P_{x i t+1} / P_{c i t+1}}{P_{x i t} / P_{c i t}}\right)^{\sigma},
$$

Combining the representative household's budget constraint, together with capital accumulation technology and rearranging, implies the following:

$$
C_{i t}=\left(1+\frac{r_{i t+1}}{P_{x i t}+1}-\delta\right)\left(\frac{P_{x i t}}{P_{c i t}}\right) K_{i t}+\left(\frac{w_{i t}}{P_{c i t}}\right) L_{i}-\left(\frac{P_{x i t}}{P_{c i t}}\right) K_{i t+1} .
$$

Firm optimization Markets are perfectly competitive, so firms set prices equal to marginal costs. Denote the price of variety $v$, produced in country $j$ and purchased by country $i$, as $p_{m i j}(v)$. Then $p_{m i j}(v)=p_{m j j}(v) d_{i j}$, where $p_{m j j}(v)$ is the marginal cost of producing variety $v$ in country $j$. Since country $i$ purchases each variety from the country that can deliver it at the lowest price, the price in country $i$ is $p_{m i}(v)=\min _{j=1, \ldots, I}\left[p_{m j j}(v) d_{m i j}\right]$. The price of the composite intermediate good in country $i$ at time $t$ is then

$$
P_{m i t}=\gamma\left[\sum_{j=1}^{I}\left(u_{j t} d_{i j}\right)^{-\theta} T_{m j}\right]^{-\frac{1}{\theta}}
$$

where $u_{j t}=\left(\frac{r_{j t}}{\alpha \nu_{m}}\right)^{\alpha \nu_{m}}\left(\frac{w_{j t}}{(1-\alpha) \nu_{m}}\right)^{(1-\alpha) \nu_{m}}\left(\frac{P_{j t}}{1-\nu_{m}}\right)^{1-\nu_{m}}$ is the unit cost for a bundle of inputs for intermediate goods producers in country $n$ at time $t$.

Next we define total factor usage in the intermediates sector by aggregating across the individual varieties.

$$
\begin{aligned}
K_{m i t} & =\int_{0}^{1} K_{m i t}(v) d v, & L_{m i t} & =\int_{0}^{1} L_{m i t}(v) d v \\
M_{m i t} & =\int_{0}^{1} M_{m i t}(v) d v, & Y_{m i t} & =\int_{0}^{1} Y_{m i t}(v) d v .
\end{aligned}
$$


The term $L_{m i t}(v)$ denotes the quantity of labor used in the production of variety $v$ at time $t$. If country $i$ imports variety $v$ at time $t$, then $L_{m i t}(v)=0$. Hence, $L_{m i t}$ is the total quantity of labor used in sector $m$ in country $i$ at time $t$. Similarly, $K_{m i t}$ is the total quantity of capital used, $M_{m i t}$ is the total quantity of intermediates used as an input, and $Y_{m i t}$ is the total quantity of output of intermediate goods.

Cost minimization by firms implies that, within each sector $b \in\{c, m, x\}$, factor expenses exhaust the value of output:

$$
\begin{aligned}
r_{i t} K_{b i t} & =\alpha \nu_{b} P_{b i t} Y_{b i t}, \\
w_{i t} L_{b i t} & =(1-\alpha) \nu_{b} P_{b i t} Y_{b i t}, \\
P_{\text {mit }} M_{b i t} & =\left(1-\nu_{b}\right) P_{b i t} Y_{b i t} .
\end{aligned}
$$

That is, the fraction $\alpha \nu_{b}$ of the value of each sector's production compensates capital services, the fraction $(1-\alpha) \nu_{b}$ compensates labor services, and the fraction $1-\nu_{b}$ covers the cost of intermediate inputs; there are zero profits.

Trade flows The fraction of country $i$ 's expenditures allocated to intermediate varieties produced by country $j$ is given by

$$
\pi_{i j t}=\frac{\left(u_{m j t} d_{i j t}\right)^{-\theta} T_{m j}}{\sum_{j=1}^{I}\left(u_{m j t} d_{i j}\right)^{-\theta} T_{m j}}
$$

where $u_{m j t}$ is the unit cost of a bundle of factors faced by producers of intermediate varieties in country $j$.

Market clearing conditions We begin by describing the domestic factor market clearing conditions.

$$
\sum_{b \in\{c, m, x\}} K_{b i t}=K_{i t}, \quad \sum_{b \in\{c, m, x\}} L_{b i t}=L_{i}, \quad \sum_{b \in\{c, m, x\}} M_{b i t}=M_{i t} .
$$

The first two conditions impose that the capital and labor markets clear in country $i$ at each time $t$. The third condition requires that the use of the composite intermediate good equals its supply. Its use consists of intermediate demand by firms in each sector. Its supply is the quantity of the composite good, which consists of both domestically and foreign-produced varieties. 
The next conditions require that goods markets clear.

$$
C_{i t}=Y_{c i t}, \quad X_{i t}=Y_{x i t}, \quad \sum_{j=1}^{I} P_{m j t}\left(M_{c j t}+M_{m j t}+M_{x j t}\right) \pi_{j i t}=P_{m i t} Y_{m i t}
$$

The first condition states that the quantity of consumption demanded by the representative household in country $i$ must equal the quantity produced by country $i$. The second condition says the same for the investment good. The third condition imposes that the value of intermediates produced by country $i$ has to be absorbed globally. Recall that $P_{m j t} M_{b j t}$ is the value of intermediate inputs that country $i$ uses in production in sector $b$. The term $\pi_{j i t}$ is the fraction of country $j$ 's intermediate good expenditures sourced from country $i$. Therefore, $P_{m j t} M_{b j t} \pi_{j i t}$ denotes the total value of trade flows from country $i$ to country $j$.

Finally, we impose an aggregate resource constraint in each country: Net exports equal zero. Equivalently, gross output equals gross absorption:

$$
P_{m i t} Y_{m i t}=P_{m i t} M_{i t}
$$

The left-hand side denotes the gross output of intermediates in country $i$ and the right-hand side denotes total expenditures on intermediates.

\section{B Data}

This Appendix describes the sources of data and any adjustments we make to the data to map it to the model.

\section{B.1 Production and trade data}

Mapping the trade dimension of our model to the data requires data on both production and international trade flows. Our focus is on manufactured intermediate goods. We interpret manufacturing broadly as defined by the International Standard Industrial Classification (ISIC).

We obtain production data from multiple sources. First, we use value added and gross output data from the INDSTAT database, which are reported at the two-digit level using ISIC. The data for countries extend no further than 2010 and even less for many countries. We turn to data on value added output in UN National Accounts Main Aggregates Database 
(UNNAMAD, http://unstats.un.org/unsd/snaama/Introduction.asp), which reports value added output for 2011. For countries that report both value added and gross output in INDSTAT, we use the ratio from the year closest to 2011 and apply that ratio to the value added from UNNAMAD to recover gross output. For countries with no data on gross output in INDSTAT for any years, we apply the average ratio of value added to gross output across all countries and apply that ratio to the value added figure in UNNAMAD for 2011. In our dataset, the ratio of value added to gross output does not vary significantly over time and is also not correlated with level of development or country size.

Our source of trade data is the UN Comtrade Database (http://comtrade.un.org). Trade is reported for goods using revision 2 Standard International Trade Classification (SITC2) at the four-digit level. We use the correspondence tables created by Affendy, Sim Yee, and Satoru (2010) to map SITC2 to ISIC. We also omit any petroleum-related products from the trade data.

Using the trade and production data, we construct bilateral trade shares for each country pair by following Bernard, Eaton, Jensen, and Kortum (2003) as follows:

$$
\pi_{i j}=\frac{X_{i j}}{A B S_{b i}},
$$

where $i$ denotes the importer and $j$ denotes the exporter. $X_{i j}$ denotes manufacturing trade flows from $j$ to $i$, and $A B S_{i}$ is country $i$ 's absorption defined as gross output less net exports of manufactures.

\section{B.2 National accounts and price data}

GDP and population For our calibration, we collect data on output-side real GDP at current Purchasing Power Parity (2005 U.S. dollars) from version 8.1 of the Penn World Tables (PWT hereafter; see Feenstra, Inklaar, and Timmer, 2015) using the variable cgdpo.

We use the variable pop from PWT to measure the population in each country. The ratio $\frac{\text { cgdpo }}{\text { pop }}$ corresponds to GDP per capita, $y$, in our model.

In our counterfactuals, we compare changes over time with past trade liberalization episodes using national accounts data from the PWT: rgdpna, rkna, and rtfpna.

We take the price level of household consumption and the price level of capital formation (both relative to the price of output-side GDP in the Unites States in constant prices) from PWT using variables $\mathrm{p} l_{-} \mathrm{c}$ and $\mathrm{p} \mathbf{l}_{-} \mathrm{i}$, respectively. These correspond to $P_{c}$ and $P_{x}$ in our model. 
We construct the price of intermediate goods (manufactures) by combining disaggregate price data from the World Bank's 2011 International Comparison Program (ICP; http://siteresources.worldbank.org/ICPEXT/Resources/ICP_2011.html). The data have several categories that fall under what we classify as manufactures: "Food and nonalcoholic beverages," "Alcoholic beverages, tobacco, and narcotics," "Clothing and foot wear," and "Machinery and equipment." The ICP reports expenditure data for these categories in both nominal U.S. dollars and real U.S. dollars. The conversion from nominal to real dollars uses the PPP price; that is, the PPP price equals the ratio of nominal expenditures to real expenditures. As such, we compute the PPP for manufactures as a whole of manufactures for each country as the sum of nominal expenditures across categories divided by the sum of real expenditures across categories.

There is one more step before we take these prices to the model. The data correspond to expenditures and thus include additional margins such as distribution. To adjust for this, we first construct a price for distribution services. We assume that the price of distribution services is proportional to the overall price of services in each country and use the same method as above to compute the price across the following categories: "Housing, water, electricity, gas, and other fuels," "Health," "Transport," "Communication," "Recreation and culture," "Education," "Restaurants and hotels," and "Construction."

Now that we have the price of services in hand, we strip it away from the price of goods computed above to arrive at a measure of the price of manufactures that better corresponds to our model. In particular, let $P_{d}$ denote the price of distribution services and let $P_{g}$ denote the price of goods that includes the distribution margin. We assume that $P_{g}=P_{d}^{\psi} P_{m}^{1-\psi}$, where $P_{m}$ is the price of manufactures. We set $\psi=0.45$, which is a value commonly used in the literature.

\section{Solution algorithm for the balanced trade model}

In this Appendix, we describe the algorithm for computing (i) the steady state and (ii) the transition path. Before going further into the algorithms, we introduce some notation. We denote the steady-state objects using the $\star$ as a superscript; that is, $K_{i}^{\star}$ is the steady-state stock of capital in country $i$. We denote the cross-country vector of capital at a point in time using vector notation; $\vec{K}_{t}=\left\{K_{i t}\right\}_{i=1}^{I}$ is the vector of capital stocks across countries at time $t$. 


\section{C.1 Computing the steady-state equilibrium in the balanced trade model}

The steady-state equilibrium consists of 22 objects: $\vec{w}^{\star}, \vec{r}^{\star}, \vec{P}_{c}^{\star}, \vec{P}_{m}^{\star}, \overrightarrow{P_{x}^{\star}}, \vec{C}^{\star}, \vec{X}^{\star}, \vec{K}^{\star}, \vec{M}^{\star}$, $\vec{Y}_{c}^{\star}, \vec{Y}_{m}^{\star}, \vec{Y}_{x}^{\star}, \vec{K}_{c}^{\star}, \vec{K}_{m}^{\star}, \vec{K}_{x}^{\star}, \vec{L}_{c}^{\star}, \vec{L}_{m}^{\star}, \vec{L}_{x}^{\star}, \vec{M}_{c}^{\star}, \vec{M}_{m}^{\star}, \vec{M}_{x}^{\star}, \overrightarrow{\vec{\pi}}^{\star}$. Table C.1 provides a list of 23 equilibrium conditions that these objects must satisfy. One market clearing equation is redundant (condition 12 in our algorithm).

We use the technique from Mutreja, Ravikumar, and Sposi (2014), which builds on Alvarez and Lucas (2007), to solve for the steady state. The idea is to guess a vector of wages, then recover all remaining prices and quantities using optimality conditions and market clearing conditions, excluding the trade balance condition. We then use departures from the trade balance condition in each country to update our wage vector and iterate until we find a wage vector that satisfies the trade balance condition. The following steps outline our procedure in more detail:

(i) We guess a vector of wages $\vec{w} \in \Delta=\left\{w \in \mathbb{R}_{+}^{I}: \sum_{i=1}^{I} \frac{w_{i} L_{i}}{1-\alpha}=1\right\}$; that is, with world GDP as the numéraire.

(ii) We compute prices $\vec{P}_{c}, \vec{P}_{x}, \vec{P}_{m}$, and $\vec{r}$ simultaneously using conditions $16,17,18$, and 23 in Table C.1. To complete this step, we compute the bilateral trade shares $\vec{\pi}$ using condition 19.

(iii) We compute the aggregate capital stock as $K_{i}=\frac{\alpha}{1-\alpha} \frac{w_{i} L_{i}}{r_{i}}$, for all $i$, which derives easily from optimality conditions 1 and 4, 2 and 5, and 3 and 6, coupled with market clearing conditions for capital and labor 10 and11 in Table C.1.

(iv) We use condition 22 to solve for steady-state investment $\vec{X}$. Then we use condition 21 to solve for steady-state consumption $\vec{C}$.

(v) We combine conditions 4 and 13 to solve for $\vec{L}_{c}$, combine conditions 5 and 14 to solve for $\vec{L}_{x}$, and use condition 11 to solve for $\vec{L}_{m}$. Next we combine conditions 1 and 4 to solve for $\vec{K}_{c}$, combine conditions 2 and 5 to solve for $\vec{K}_{M}$, and combine conditions 3 and 6 to solve for $\vec{K}_{x}$. Similarly, we combine conditions 4 and 7 to solve for $\vec{M}_{c}$, combine conditions 5 and 8 to solve for $\vec{M}_{m}$, and combine conditions 6 and 9 to solve for $\vec{M}_{x}$.

(vi) We compute $\vec{Y}_{c}$ using condition 13 , compute $\vec{Y}_{m}$ using condition 14 , and compute $\vec{Y}_{x}$ using condition 15. 
Table C.1: Steady-state equilibrium conditions in balanced trade model

\begin{tabular}{lll}
\hline \hline 1 & $r_{i}^{\star} K_{c i}^{\star}=\alpha \nu_{c} P_{c i}^{\star} Y_{c i}^{\star}$ & $\forall(i)$ \\
2 & $r_{i}^{\star} K_{m i}^{\star}=\alpha \nu_{m} P_{m i}^{\star} Y_{m i}^{\star}$ & $\forall(i)$ \\
3 & $r_{i}^{\star} K_{x i}^{\star}=\alpha \nu_{x} P_{x i}^{\star} Y_{x i}^{\star}$ & $\forall(i)$ \\
4 & $w_{i}^{\star} L_{c i}^{\star}=(1-\alpha) \nu_{c} P_{c i}^{\star} Y_{c i}^{\star}$ & $\forall(i)$ \\
5 & $w_{i}^{\star} L_{m i}^{\star}=(1-\alpha) \nu_{m} P_{m i}^{\star} Y_{m i}^{\star}$ & $\forall(i)$ \\
6 & $w_{i}^{\star} L_{x i}^{\star}=(1-\alpha) \nu_{x} P_{x i}^{\star} Y_{x i}^{\star}$ & $\forall(i)$ \\
7 & $P_{m i}^{\star} M_{c i}^{\star}=\left(1-\nu_{c}\right) P_{c i}^{\star} Y_{c i}^{\star}$ & $\forall(i)$ \\
8 & $P_{m i}^{\star} M_{m i}^{\star}=\left(1-\nu_{m}\right) P_{m i}^{\star} Y_{m i}^{\star}$ & $\forall(i)$ \\
9 & $P_{m i}^{\star} M_{x i}^{\star}=\left(1-\nu_{x}\right) P_{x i}^{\star} Y_{x i}^{\star}$ & $\forall(i)$ \\
10 & $K_{c i}^{\star}+K_{m i}^{\star}+K_{x i}^{\star}=K_{i}^{\star}$ & $\forall(i)$ \\
11 & $L_{c i}^{\star}+L_{m i}^{\star}+L_{x i}^{\star}=L_{i}$ & $\forall(i)$ \\
12 & $M_{c i}^{\star}+M_{m i}^{\star}+M_{x i}^{\star}=M_{i}^{\star}$ & $\forall(i)$ \\
13 & $C_{i}^{\star}=Y_{c i}^{\star}$ & $\forall(i)$ \\
14 & $\sum_{j=1}^{I} P_{m j}^{\star}\left(M_{c j}^{\star}+M_{m j}^{\star}+M_{x j}^{\star}\right) \pi_{j i}=P_{m i}^{\star} Y_{m i}^{\star}$ & $\forall(i)$ \\
15 & $X_{i}^{\star}=Y_{x i}^{\star}$ & $\forall(i)$ \\
16 & $P_{c i}^{\star}=\left(\frac{1}{A_{c i}}\right)\left(\frac{r_{i}^{\star}}{\alpha \nu_{c}}\right)^{\alpha \nu_{c}}\left(\frac{w_{i}^{\star}}{(1-\alpha) \nu_{c}}\right)^{(1-\alpha) \nu_{c}}\left(\frac{P_{m i}^{\star}}{1-\nu_{c}}\right)^{1-\nu_{c}}$ & $\forall(i)$ \\
17 & $P_{m i}^{\star}=\gamma\left[\sum_{j=1}^{I}\left(u_{m j}^{\star} d_{i j}\right)^{-\theta} T_{m j}\right.$ & \\
18 & $P_{x i}^{\star}=\left(\frac{1}{A_{x i}}\right)\left(\frac{r_{i}^{\star}}{\alpha \nu_{x}}\right)^{\alpha \nu_{x}}\left(\frac{w_{i}^{\star}}{(1-\alpha) \nu_{x}}\right)^{(1-\alpha) \nu_{x}}\left(\frac{P_{m i}^{\star}}{1-\nu_{x}}\right)^{1-\nu_{x}}$ & $\forall(i)$ \\
19 & $\pi_{i j}^{\star}=\frac{\left(u_{m j}^{\star} d_{i j}\right)^{-\theta} T_{m j}}{\sum_{j=1}^{I}\left(u_{m j}^{\star} d_{i j}\right)^{-\theta} T_{m j}}$ & $\forall(i)$ \\
20 & $P_{m i}^{\star} Y_{m i}^{\star}=P_{m i}^{\star} M_{i}^{\star}$ & $\forall(i, j)$ \\
21 & $P_{c i}^{\star} C_{i}^{\star}+P_{x i}^{\star} X_{i}^{\star}=r_{i}^{\star} K_{i}^{\star}+w_{i}^{\star} L_{i}^{\star}$ & $\forall(i)$ \\
22 & $X_{i}^{\star}=\delta K_{i}^{\star}$ & $\forall(i)$ \\
23 & $r_{i}^{\star}=\left(\frac{1}{\beta}-(1-\delta)\right) P_{x i}^{\star}$ & $\forall(i)$ \\
\hline \multirow{2}{*}{ Note: $u_{m j}^{\star}=\left(\frac{r_{j}^{\star}}{\alpha \nu_{m}}\right)^{\alpha \nu_{m}}\left(\frac{w_{j}^{\star}}{(1-\alpha) \nu_{m}}\right)^{(1-\alpha) \nu_{m}}\left(\frac{P_{m j}^{\star}}{1-\nu_{m}}\right)^{1-\nu_{m}}$} & $\forall(i)$ \\
& &
\end{tabular}


(vii) We compute an excess demand equation as in Alvarez and Lucas (2007) defined as

$$
Z_{i}(\vec{w})=\frac{P_{m i} Y_{m i}-P_{m i} M_{i}}{w_{i}}
$$

(the trade deficit relative to the wage). Condition 20 requires that $Z_{i}(\vec{w})=0$ for all $i$. If the excess demand is sufficiently close to 0 , then we have an equilibrium. If not, we update our guess at the equilibrium wage vector using the information in the excess demand as follows:

$$
\Lambda_{i}(\vec{w})=w_{i}\left(1+\psi \frac{Z_{i}(\vec{w})}{L_{i}}\right)
$$

which is the updated guess to the wage vector, where $\psi$ is chosen to be sufficiently small so that $\Lambda>0$. Note that $\sum_{i=1}^{I} \frac{\Lambda_{i}(\vec{w}) L_{i}}{1-\alpha}=\sum_{i=1}^{I} \frac{w_{i} L_{i}}{1-\alpha}+\psi \sum_{i=1}^{I} w_{i} Z_{i}(\vec{w})$. As in Alvarez and Lucas (2007), it is easy to show that $\sum_{i=1}^{I} w_{i} Z_{i}(\vec{w})=0$ which implies that $\sum_{i=1}^{I} \frac{\Lambda_{i}(\vec{w}) L_{i}}{1-\alpha}=1$, and hence, $\Lambda: \Delta \rightarrow \Delta$. We return to step (ii) with our updated wage vector and repeat the steps. We iterate through this procedure until the excess demand is sufficiently close to 0 . In our computations we find that our preferred convergence metric,

$$
\max _{i=1}^{I}\left\{\left|Z_{i}(\vec{w})\right|\right\}
$$

converges roughly monotonically towards 0 .

\section{C.2 Computing the equilibrium transition path in the balanced trade model}

The equilibrium transition path consists of 22 objects: $\left\{\vec{w}_{t}\right\}_{t=1}^{\infty},\left\{\vec{r}_{t}\right\}_{t=1}^{\infty},\left\{\vec{P}_{c t}\right\}_{t=1}^{\infty},\left\{\vec{P}_{m t}\right\}_{t=1}^{\infty}$, $\left\{\vec{P}_{x t}\right\}_{t=1}^{\infty},\left\{\vec{C}_{t}\right\}_{t=1}^{\infty},\left\{\vec{X}_{t}\right\}_{t=1}^{\infty},\left\{\vec{K}_{t}\right\}_{t=1}^{\infty},\left\{\vec{Q}_{m t}\right\}_{t=1}^{\infty},\left\{\vec{Y}_{c t}\right\}_{t=1}^{\infty},\left\{\vec{Y}_{m t}\right\}_{t=1}^{\infty},\left\{\vec{Y}_{x t}\right\}_{t=1}^{\infty},\left\{\vec{K}_{c t}\right\}_{t=1}^{\infty},\left\{\vec{K}_{m t}\right\}_{t=1}^{\infty}$, $\left\{\vec{K}_{x t}\right\}_{t=1}^{\infty},\left\{\vec{L}_{c t}\right\}_{t=1}^{\infty},\left\{\vec{L}_{m t}\right\}_{t=1}^{\infty},\left\{\vec{L}_{x t}\right\}_{t=1}^{\infty},\left\{\vec{M}_{c t}\right\}_{t=1}^{\infty},\left\{\vec{M}_{m t}\right\}_{t=1}^{\infty},\left\{\vec{M}_{x t}\right\}_{t=1}^{\infty},\left\{\overrightarrow{\vec{\pi}}_{t}\right\}_{t=1}^{\infty}$ (we use the double-arrow notation on $\overrightarrow{\vec{\pi}}_{t}$ to indicate that this is an $I \times I$ matrix in each period $t$ ). Table C.2 provides a list of equilibrium conditions that these objects must satisfy.

We reduce the infinite dimensionality to a finite time problem from $t=1, \ldots, T$, with $T$ sufficiently large to ensure that the endogenous variables settle to a steady state by $T$. As such, solving the transition first requires solving the terminal steady state. Also, it requires taking an initial stock of capital as given (either by computing an initial steady state or just taking it from data, for instance).

Our solution method mimics the idea of that for the steady state but is slightly modified to take into account the dynamic aspect as in Sposi (2012). Basically, we start with an 
Table C.2: Dynamic equilibrium conditions in balanced trade model

\begin{tabular}{lll}
\hline \hline 1 & $r_{i t} K_{c i t}=\alpha \nu_{c} P_{c i t} Y_{c i t}$ & $\forall(i, t)$ \\
2 & $r_{i t} K_{m i t}=\alpha \nu_{m} P_{m i t} Y_{m i t}$ & $\forall(i, t)$ \\
3 & $r_{i t} K_{x i t}=\alpha \nu_{x} P_{x i t} Y_{x i t}$ & $\forall(i, t)$ \\
4 & $w_{i t} L_{c i t}=(1-\alpha) \nu_{c} P_{c i t} Y_{c i t}$ & $\forall(i, t)$ \\
5 & $w_{i t} L_{m i t}=(1-\alpha) \nu_{m} P_{m i t} Y_{m i t}$ & $\forall(i, t)$ \\
6 & $w_{i t} L_{x i t}=(1-\alpha) \nu_{x} P_{x i t} Y_{x i t}$ & $\forall(i, t)$ \\
7 & $P_{m i t} M_{c i t}=\left(1-\nu_{c}\right) P_{c i t} Y_{c i t}$ & $\forall(i, t)$ \\
8 & $P_{m i t} M_{m i t}=\left(1-\nu_{m}\right) P_{m i t} Y_{m i t}$ & $\forall(i, t)$ \\
9 & $P_{m i t} M_{x i t}=\left(1-\nu_{x}\right) P_{x i t} Y_{x i t}$ & $\forall(i, t)$ \\
10 & $K_{c i t}+K_{m i t}+K_{x i t}=K_{i t}$ & $\forall(i, t)$ \\
11 & $L_{c i t}+L_{m i t}+L_{x i t}=L_{i}$ & $\forall(i, t)$ \\
12 & $M_{c i t}+M_{m i t}+M_{x i t}=M_{i t}$ & $\forall(i, t)$ \\
13 & $C_{i t}=Y_{c i t}$ & $\forall(i, t)$ \\
14 & $\sum_{j=1}^{I} P_{m j t}\left(M_{c j t}+M_{m j t}+M_{x j t}\right) \pi_{j i t}=P_{m i t} Y_{m i t}$ & $\forall(i, t)$ \\
15 & $X_{i t}=Y_{x i t}$ & $\forall(i, t)$ \\
16 & $P_{c i t}=\left(\frac{1}{A_{c i}}\right)\left(\frac{r_{i t}}{\alpha \nu_{c}}\right)^{\alpha \nu_{c}}\left(\frac{w_{i t}}{(1-\alpha) \nu_{c}}\right)^{(1-\alpha) \nu_{c}}\left(\frac{P_{m i t}}{1-\nu_{c}}\right)^{1-\nu_{c}}$ & $\forall(i, t)$ \\
17 & $P_{m i t}=\gamma\left[\sum_{j=1}^{I}\left(u_{m j t} d_{i j}\right)^{-\theta} T_{m j}\right]^{-\frac{1}{\theta}}$ & $\forall(i, t)$ \\
18 & $P_{x i t}=\left(\frac{1}{A_{x i}}\right)\left(\frac{r_{i t}}{\alpha \nu_{x}}\right)^{\alpha \nu_{x}}\left(\frac{w_{i t}}{(1-\alpha) \nu_{x}}\right)^{(1-\alpha) \nu_{x}}\left(\frac{P_{m i t}}{1-\nu_{x}}\right)^{1-\nu_{x}}$ & $\forall(i, t)$ \\
19 & $\pi_{i j t}=\frac{\left(u_{m j t} d_{i j}\right)^{-\theta} T_{m j}}{\sum_{j=1}^{I}\left(u_{m j t} d_{i j}\right)^{-\theta} T_{m j}}$ & $\forall(i, j, t)$ \\
20 & $P_{m i t} Y_{m i t}=P_{m i t} M_{i t}$ & $\forall(i, t)$ \\
21 & $P_{c i t} C_{i t}+P_{x i t} X_{i t}=r_{i t} K_{i t}+w_{i t} L_{i}$ & $\forall(i, t)$ \\
22 & $K_{i t+1}=(1-\delta) K_{i t}+X_{i t}$ & $\forall(i, t)$ \\
23 & $\left(\frac{C_{i t+1}}{C_{i t}}\right)=\beta^{\sigma}\left(1+\frac{r_{i t+1}}{P_{x i t+1}}-\delta\right)^{\sigma}\left(\frac{P_{x t+1} / P_{c t+1}}{P_{x t} / P_{c t}}\right)^{\sigma}$ & $\forall(i, t)$ \\
\hline \multirow{2}{*}{ Note: $u_{m j t}=\left(\frac{r_{j t}}{\alpha \nu_{m}}\right)^{\alpha \nu_{m}}\left(\frac{w_{j t}}{(1-\alpha) \nu_{m}}\right)^{(1-\alpha) \nu_{m}}\left(\frac{P_{m j t}}{1-\nu_{m}}\right)^{1-\nu_{m}}$} & \\
& &
\end{tabular}


initial guess for the entire sequence of wage vectors and rental rates (across countries and over time). From these two objects we can recover all prices and quantities, across countries and throughout time, using optimality conditions and market clearing conditions, excluding the trade balance condition and the market clearing condition for the stock of capital. We then use departures from the trade balance condition and the market clearing condition for the stock of capital at each point in time and in each country to update our wages and rental rates. Then we iterate until we find wages and rental rates that satisfy the trade balance condition and the market clearing condition for the stock of capital. We describe the steps to our procedure in more detail below.

(i) We guess the entire path for wages $\left\{\vec{w}_{t}\right\}_{t=1}^{T}$ and rental rates $\left\{\vec{r}_{t}\right\}_{t=2}^{T}$ across countries, such that $\sum_{i} \frac{w_{i t} L_{i}}{1-\alpha}=1(\forall t)$. In period 1 , set $\vec{r}_{1}=\left(\frac{\alpha}{1-\alpha}\right)\left(\frac{\vec{w}_{1} \vec{L}}{\vec{K}_{1}}\right)$ since the initial stock of capital is predetermined.

(ii) We compute prices $\left\{\vec{P}_{c t}\right\}_{t=1}^{T},\left\{\vec{P}_{x t}\right\}_{t=1}^{T}$, and $\left\{\vec{P}_{m t}\right\}_{t=1}^{T}$ simultaneously using conditions 16, 17, and 18, in Table C.2. To complete this step, we compute the bilateral trade shares $\left\{\overrightarrow{\vec{\pi}}_{t}\right\}_{t=1}^{T}$ using condition 19 .

(iii) This step is slightly more involved. We show how we compute the path for consumption and investment by solving the intertemporal problem of the household. We do this in three steps. First, we derive the lifetime budget constraint. Second, we derive the fraction of lifetime wealth allocated to consumption at each period $t$. And third, we recover the sequence for investment and the stock of capital.

Deriving the lifetime budget constraint To begin, we compute the lifetime budget constraint for the representative household in country $i$. Begin with the period budget constraint from condition 21 and combine it with the capital accumulation technology in condition 22 to get

$$
K_{i t+1}=\left(\frac{w_{i t}}{P_{x i t}}\right) L_{i}+\left(1+\frac{r_{i t}}{P_{x i t}}-\delta\right) K_{i t}-\left(\frac{P_{c i t}}{P_{x i t}}\right) C_{i t} .
$$

We iterate the period budget constraint forward through time and derive a lifetime budget constraint. At time $t=1$, the stock of capital, $K_{i 1}>0$, is given. Next, 
compute the stock of capital at time $t=2$ :

$$
K_{i 2}=\left(\frac{w_{i 1}}{P_{x i 1}}\right) L_{i}+\left(1+\frac{r_{i 1}}{P_{x i 1}}-\delta\right) K_{i 1}-\left(\frac{P_{c i 1}}{P_{x i 1}}\right) C_{i 1} .
$$

Similarly, compute the stock of capital at time $t=3$, but do it so that it is in terms the initial stock of capital.

$$
\begin{aligned}
K_{i 3} & =\left(\frac{w_{i 2}}{P_{x i 2}}\right) L_{i}+\left(1+\frac{r_{i 2}}{P_{x i 2}}-\delta\right) K_{i 2}-\left(\frac{P_{c i 2}}{P_{x i 2}}\right) C_{i 2} . \\
\Rightarrow K_{i 3} & =\left(\frac{w_{i 2}}{P_{x i 2}}\right) L_{i 2}+\left(1+\frac{r_{i 2}}{P_{x i 2}}-\delta\right)\left(\frac{w_{i 1}}{P_{x i 1}}\right) L_{i} \\
& +\left(1+\frac{r_{i 2}}{P_{x i 2}}-\delta\right)\left(1+\frac{r_{i 1}}{P_{x i 1}}-\delta\right) K_{i 1} \\
& -\left(1+\frac{r_{i 2}}{P_{x i 2}}-\delta\right)\left(\frac{P_{c i 1}}{P_{x i 1}}\right) C_{i 1}-\left(\frac{P_{c i 2}}{P_{x i 2}}\right) C_{i 2}
\end{aligned}
$$

Continue to period 4 in a similar way:

$$
\begin{aligned}
K_{i 4} & =\left(\frac{w_{i 3}}{P_{x i 3}}\right) L_{i}+\left(1+\frac{r_{i 3}}{P_{x i 3}}-\delta\right) K_{i 3}-\left(\frac{P_{c i 3}}{P_{x i 3}}\right) C_{i 3} \\
\Rightarrow K_{i 4} & =\left(\frac{w_{i 3}}{P_{x i 3}}\right) L_{i}+\left(1+\frac{r_{i 3}}{P_{x i 3}}-\delta\right)\left(\frac{w_{i 2}}{P_{x i 2}}\right) L_{i} \\
& +\left(1+\frac{r_{i 3}}{P_{x i 3}}-\delta\right)\left(1+\frac{r_{i 2}}{P_{x i 2}}-\delta\right)\left(\frac{w_{i 1}}{P_{x i 1}}\right) L_{i} \\
& +\left(1+\frac{r_{i 3}}{P_{x i 3}}-\delta\right)\left(1+\frac{r_{i 2}}{P_{x i 2}}-\delta\right)\left(1+\frac{r_{i 1}}{P_{x i 1}}-\delta\right) K_{i 1} \\
& -\left(1+\frac{r_{i 3}}{P_{x i 3}}-\delta\right)\left(1+\frac{r_{i 2}}{P_{x i 2}}-\delta\right)\left(\frac{P_{c i 1}}{P_{x i 1}}\right) C_{i 1} \\
& -\left(1+\frac{r_{i 3}}{P_{x i 3}}-\delta\right)\left(\frac{P_{c i 2}}{P_{x i 2}}\right) C_{i 2}-\left(\frac{P_{c i 3}}{P_{x i 3}}\right) C_{i 3} .
\end{aligned}
$$


Before we continue, it is useful to define $\left(1+R_{i t}\right) \equiv \prod_{n=1}^{t}\left(1+\frac{r_{i n}}{P_{x i n}}-\delta\right)$. Then:

$$
\begin{aligned}
\Rightarrow K_{i 4} & =\frac{\left(1+R_{i 3}\right)\left(\frac{w_{i 3}}{P_{x i 3}}\right) L_{i}}{\left(1+R_{i 3}\right)}+\frac{\left(1+R_{i 3}\right)\left(\frac{w_{i 2}}{P_{x i 2}}\right) L_{i 2}}{\left(1+R_{i 2}\right)}+\frac{\left(1+R_{i 3}\right)\left(\frac{w_{i 1}}{P_{x i 1}}\right) L_{i}}{\left(1+R_{i 1}\right)} \\
& +\left(1+R_{i 3}\right) K_{i 1} \\
& -\frac{\left(1+R_{i 3}\right)\left(\frac{P_{c i 3}}{P_{x i 3}}\right) C_{i 3}}{\left(1+R_{i 3}\right)}-\frac{\left(1+R_{i 3}\right)\left(\frac{P_{c i 2}}{P_{x i 2}}\right) C_{i 2}}{\left(1+R_{i 2}\right)}-\frac{\left(1+R_{i 3}\right)\left(\frac{P_{c i 1}}{P_{x i 1}}\right) C_{i 1}}{\left(1+R_{i 1}\right)} \\
\Rightarrow K_{i 4} & =\sum_{n=1}^{3} \frac{\left(1+R_{i 3}\right)\left(\frac{w_{i n}}{P_{x i n}}\right) L_{i n}}{\left(1+R_{i n}\right)}-\sum_{n=1}^{3} \frac{\left(1+R_{i 3}\right)\left(\frac{P_{c i n}}{P_{x i n}}\right) C_{i n}}{\left(1+R_{i n}\right)}+\left(1+R_{i 3}\right) K_{i 1} .
\end{aligned}
$$

By induction, for any time $t$,

$$
\begin{aligned}
K_{i t+1} & =\sum_{n=1}^{t} \frac{\left(1+R_{i t}\right)\left(\frac{w_{i n}}{P_{x i n}}\right) L_{i}}{\left(1+R_{i n}\right)}-\sum_{n=1}^{t} \frac{\left(1+R_{i t}\right)\left(\frac{P_{\text {cin }}}{P_{\text {xin }}}\right) C_{i n}}{\left(1+R_{\text {in }}\right)}+\left(1+R_{i t}\right) K_{i 1} \\
\Rightarrow K_{i t+1} & =\left(1+R_{i t}\right)\left(\sum_{n=1}^{t} \frac{\left(\frac{w_{i n}}{P_{x i n}}\right) L_{i}}{\left(1+R_{i n}\right)}-\sum_{n=1}^{t} \frac{\left(\frac{P_{\text {cin }}}{P_{x i n}}\right) C_{i n}}{\left(1+R_{i n}\right)}+K_{i 1}\right) .
\end{aligned}
$$

Finally, observe the previous expression as of $t=T$ and rearrange terms to derive the lifetime budget constraint:

$$
\sum_{n=1}^{T} \frac{P_{\text {cin }} C_{i n}}{P_{x i n}\left(1+R_{i n}\right)}=\underbrace{\sum_{n=1}^{T} \frac{w_{i n} L_{i}}{P_{x i n}\left(1+R_{i n}\right)}+K_{i 1}-\frac{K_{i T+1}}{\left(1+R_{i T}\right)}}_{W_{i}} .
$$

In the lifetime budget constraint (C.1), we use $W_{i}$ to denote the net present value of lifetime wealth in country $i$, and we take the capital stock at the end of time, $K_{i T+1}$, as given; in our case, it is the capital stock in the new steady state with $T$ sufficiently large. Note that by imposing the terminal condition that $K_{i T+1}=K_{i}^{\star}$, the transversality condition is automatically satisfied since $\lim _{T \rightarrow \infty}\left(1+R_{i T}\right)=\infty$ and $\lim _{T \rightarrow \infty} K_{i T+1}=K_{i}^{\star}$.

Solving for the path of consumption Next we compute how the lifetime consumption expenditures will be allocated throughout time. The Euler equation (condition 23) implies the following relationship between consumption in any two periods $t$ and 
$n:$

$$
\begin{gathered}
C_{i n}=\beta^{\sigma(n-t)}\left(\frac{\left(1+R_{i n}\right)}{\left(1+R_{i t}\right)}\right)^{\sigma}\left(\frac{P_{x i n}}{P_{x i t}}\right)^{\sigma}\left(\frac{P_{c i t}}{P_{c i n}}\right)^{\sigma} C_{i t} \\
\Rightarrow \frac{P_{c i n} C_{i n}}{P_{x i n}\left(1+R_{i n}\right)}=\beta^{\sigma(n-t)}\left(\frac{P_{x i n}\left(1+R_{i n}\right)}{P_{x i t}\left(1+R_{i t}\right)}\right)^{\sigma-1}\left(\frac{P_{c i n}}{P_{c i t}}\right)^{1-\sigma}\left(\frac{P_{c i t} C_{i t}}{P_{x i t}\left(1+R_{i t}\right)}\right) .
\end{gathered}
$$

Since equation $\mathrm{C} .1$ implies that $\sum_{n=1}^{T} \frac{P_{\operatorname{cin}} C_{i n}}{P_{x i n}\left(1+R_{i n}\right)}=W_{i}$, then we can rearrange the previous expression to obtain

$$
\frac{P_{c i t} C_{i t}}{P_{x i t}\left(1+R_{i t}\right)}=\underbrace{\left(\frac{\beta^{\sigma t} P_{x i t}^{\sigma-1}\left(1+R_{i t}\right)^{\sigma-1} P_{c i t}^{1-\sigma}}{\sum_{n=1}^{T} \beta^{\sigma n} P_{x i n}^{\sigma-1}\left(1+R_{i n}\right)^{\sigma-1} P_{c i n}^{1-\sigma}}\right)}_{\xi_{i t}} W_{i} .
$$

That is, each period the household spends a share $\xi_{i t}$ of lifetime wealth on consumption, with $\sum_{t=1}^{T} \xi_{i t}=1$ for all $i$. Note that $\xi_{i t}$ depends only on prices.

Computing investment and the sequence of capital stocks Given paths of consumption, solve for investment $\left\{\vec{X}_{t}\right\}_{t=1}^{T}$ using the period budget constraint in condition 21. The catch here is that there is no restriction that household investment be nonnegative up to this point. Looking ahead, there is no way that negative investment can satisfy market clearing conditions together with firm optimality conditions. As such, we restrict our attention to transition paths for which investment is always positive, which we find is the case for the equilibrium outcomes in our paper. However, off the equilibrium path, if during the course of the iterations any given value of $X_{i t}$ is negative, then we set it equal to a small positive number.

The last part of this step is to use condition 22 to compute the path for the stock of capital. $\left\{\vec{K}_{t}\right\}_{t=2}^{T+1}$. Note that $\vec{K}_{1}$ is taken as given and that $\vec{K}_{T+1}$ is by construction equal to the terminal steady-state value.

(iv) We combine conditions 4 and 13 to solve for $\left\{\vec{L}_{c t}\right\}_{t=1}^{T}$, combine conditions 5 and 14 to solve for $\left\{\vec{L}_{x t}\right\}_{t=1}^{T}$, and use condition 11 to solve for $\left\{\vec{L}_{m t}\right\}_{t=1}^{T}$. Next we combine conditions 1 and 4 to solve for $\left\{\vec{K}_{c t}\right\}_{t=1}^{T}$, combine conditions 2 and 5 to solve for $\left\{\vec{K}_{m t}\right\}_{t=1}^{T}$, and combine conditions 3 and 6 to solve for $\left\{\vec{K}_{x t}\right\}_{t=1}^{T}$. Similarly, we combine conditions 4 and 7 to solve for $\left\{\vec{M}_{c t}\right\}_{t=1}^{T}$, combine conditions 5 and 8 to solve for $\left\{\vec{M}_{m t}\right\}_{t=1}^{T}$, and combine conditions 6 and 9 to solve for $\left\{\vec{M}_{x t}\right\}_{t=1}^{T}$. 
(v) We compute $\left\{\vec{Y}_{c t}\right\}_{t=1}^{T}$ using condition 13, compute $\left\{\vec{Y}_{m t}\right\}_{t=1}^{T}$ using condition 14, and compute $\left\{\vec{Y}_{x t}\right\}_{t=1}^{T}$ using condition 15 .

(vi) Until this point, we have imposed all equilibrium conditions except for two: The trade balance condition 20 and the capital market clearing condition 10 .

Trade balance condition We compute an excess demand equation as in Alvarez and Lucas (2007) defined as

$$
Z_{i t}^{w}\left(\left\{\vec{w}_{t}, \vec{r}_{t}\right\}_{t=1}^{T}\right)=\frac{P_{m i t} Y_{m i t}-P_{m i t} M_{i t}}{w_{i t}},
$$

(the trade deficit relative to the wage). Condition 20 requires that $Z_{i t}^{w}\left(\left\{\vec{w}_{t}, \vec{r}_{t}\right\}_{t=1}^{T}\right)=0$ for all $i$. If this is different from zero in at least some country at some point in time we update our guess at the wages as follows:

$$
\Lambda_{i t}^{w}\left(\left\{\vec{w}_{t}, \vec{r}_{t}\right\}_{t=1}^{T}\right)=w_{i t}\left(1+\psi \frac{Z_{i t}^{w}\left(\left\{\vec{w}_{t}, \vec{r}_{t}\right\}_{t=1}^{T}\right)}{L_{i}}\right)
$$

is the updated guess to the wages, where $\psi$ is chosen to be sufficiently small so that $\Lambda^{w}>0$.

Market clearing condition for the stock of capital We compute an excess demand equation defined as

$$
Z_{i t}^{r}\left(\left\{\vec{w}_{t}, \vec{r}_{t}\right\}_{t=1}^{T}\right)=\frac{w_{i t} L_{i}}{1-\alpha}-\frac{r_{i t} K_{i t}}{\alpha}
$$

Using conditions 1-6, we have imposed that within each sector $\frac{r_{i t} K_{b i t}}{\alpha}=\frac{w_{i t} L_{b i t}}{1-\alpha}$. We have also imposed condition 11 that the labor market clears. Hence, the market for capital is in excess demand (i.e., $K_{\text {cit }}+K_{\text {mit }}+K_{x i t}>K_{i t}$ ) in country $i$ at time $t$ if and only if $\left(\frac{w_{i t} L_{i}}{1-\alpha}\right)>\left(\frac{r_{i t} K_{i t}}{\alpha}\right)$ (it is in excess supply if and only if the inequality is $<$ ). If this condition does not hold with equality in some country at some point in time, then we update our guess for rental rates as follows. Let

$$
\Lambda_{i t}^{r}\left(\left\{\vec{w}_{t}, \vec{r}_{t}\right\}_{t=1}^{T}\right)=\left(\frac{\alpha}{1-\alpha}\right)\left(\frac{L_{i}}{K_{i t}}\right) \Lambda_{i t}^{w}\left(\left\{\vec{w}_{t}, \vec{r}_{t}\right\}_{t=1}^{T}\right)
$$


be the updated guess to the rental rates (taking into account the updated guess for wages).

We return to step (ii) with our updated wages and rental rates and repeat the steps. We iterate through this procedure until the excess demand is sufficiently close to 0 . In our computations we find that our preferred convergence metric,

$$
\max _{t=1}^{T}\left\{\max _{i=1}^{I}\left\{\left|Z_{i t}^{w}\left(\left\{\vec{w}_{t}, \vec{r}_{t}\right\}_{t=1}^{T}\right)\right|+\left|Z_{i t}^{r}\left(\left\{\vec{w}_{t}, \vec{r}_{t}\right\}_{t=1}^{T}\right)\right|\right\}\right\}
$$

converges roughly monotonically toward zero.

Along the equilibrium transition, $\sum_{i} w_{i t} L_{i}+r_{i t} K_{i t}=1(\forall t)$; that is, we have chosen world GDP as the numéraire at each point in time.

The fact that $\vec{K}_{T+1}=\vec{K}^{\star}$ at each iteration is a huge benefit of our algorithm compared with algorithms that rely on a shooting algorithm or those that rely on using the Euler equation for updating. Such algorithms inherit the instability (saddle-path) properties of the Euler equation and generate highly volatile terminal stocks of capital with respect to the initial guess. Instead, we impose the Euler equation and the terminal condition for $\vec{K}_{T+1}=\vec{K}^{\star}$ at each iteration and use excess demand equations for our updating rules, just as in the computation of static models such as Alvarez and Lucas (2007). Another main advantage of using excess demand iteration is that we do not need to compute gradients to choose step directions or step size, as is the case of most nonlinear solvers such as the ones used by Eaton, Kortum, Neiman, and Romalis (2016) and Kehoe, Ruhl, and Steinberg (2016). This saves a tremendous amount of computational time, particularly as the number of countries or the number of time periods is increased.

\section{Derivations}

This Appendix shows the derivations of key structural relationships in the balanced trade model. We refer to Table C.2 for the basis of the derivations and omit time subscripts to ease notation. We begin by deriving an expression for $\frac{w_{i}}{P_{m i}}$ that will be used repeatedly.

Combining conditions 17 and 19, we obtain

$$
\pi_{i i}=\gamma^{-\theta}\left(\frac{u_{m i}^{-\theta} T_{m i}}{P_{m i}^{-\theta}}\right) .
$$

Use the fact that $u_{m i}=B_{m} r_{i}^{\alpha \nu_{m}} w_{i}^{(1-\alpha) \nu_{m}} P_{m i}^{1-\nu_{m}}$, where $B_{m}$ is a collection of constants; then 
rearrange to obtain

$$
\begin{aligned}
P_{m i} & =\left(\frac{T_{m i}}{\pi_{i i}}\right)^{-\frac{1}{\theta}}\left(\frac{r_{i}}{w_{i}}\right)^{\alpha \nu_{m}}\left(\frac{w_{i}}{P_{m i}}\right)^{\nu_{m}} P_{m i} \\
\Rightarrow \frac{w_{i}}{P_{m i}} & =\left(\frac{\left(\frac{T_{m i}}{\pi_{i i}}\right)^{\frac{1}{\theta}}}{\gamma B_{m}}\right)^{\frac{1}{\nu_{m}}}\left(\frac{w_{i}}{r_{i}}\right)^{\alpha} .
\end{aligned}
$$

Note that this relationship holds in both the steady state and along the transition.

Relative prices We show how to derive the price of consumption relative to intermediates; the relative price of investment is analogous. Begin with condition 16 to obtain

$$
P_{c i}=\left(\frac{B_{c}}{A_{c i}}\right)\left(\frac{r_{i}}{w_{i}}\right)^{\alpha \nu_{c}}\left(\frac{w_{i}}{P_{m i}}\right)^{\nu_{c}} P_{m i},
$$

where $B_{c}$ is a collection of constants. Substitute equation (D.1) into the previous expression and rearrange to obtain

$$
\frac{P_{c i}}{P_{m i}}=\left(\frac{B_{c}}{A_{c i}}\right)\left(\frac{\left(\frac{T_{m i}}{\pi_{i i}}\right)^{\frac{1}{\theta}}}{\gamma B_{m}}\right)^{\frac{\nu_{c}}{\nu_{m}}}
$$

Analogously,

$$
\frac{P_{x i}}{P_{m i}}=\left(\frac{B_{x}}{A_{x i}}\right)\left(\frac{\left(\frac{T_{m i}}{\pi_{i i}}\right)^{\frac{1}{\theta}}}{\gamma B_{m}}\right)^{\frac{\nu_{x}}{\nu_{m}}} .
$$

Note that these relationships hold in both the steady state and along the transition.

Capital-labor ratio We derive a structural relationship for the capital-labor ratio in the steady state only and make reference to conditions in Table C.1. Conditions 1-6 together with conditions 10 and 11 imply that

$$
\frac{K_{i}}{L_{i}}=\left(\frac{\alpha}{1-\alpha}\right)\left(\frac{w_{i}}{r_{i}}\right) .
$$

Using condition 23, we know that

$$
r_{i}=\left(\frac{1}{\beta}-(1-\delta)\right) P_{x i},
$$


which, by substituting into the prior expression, implies that

$$
\frac{K_{i}}{L_{i}}=\left(\frac{\alpha}{(1-\alpha)\left(\frac{1}{\beta}-(1-\delta)\right)}\right)\left(\frac{w_{i}}{P_{x i}}\right) \text {, }
$$

which leaves the problem of solving for $\frac{w_{i}}{P_{x i}}$. Equations (D.1) and (D.3) imply

$$
\begin{aligned}
\frac{w_{i}}{P_{x i}} & =\left(\frac{w_{i}}{P_{m i}}\right)\left(\frac{P_{m i}}{P_{x i}}\right) \\
& =\left(\frac{A_{x i}}{B_{x}}\right)\left(\frac{\left(\frac{T_{m i}}{\pi_{i i}}\right)^{\frac{1}{\theta}}}{\gamma B_{m}}\right)^{\frac{1-\nu_{x}}{\nu m}}\left(\frac{w_{i}}{r_{i}}\right)^{\alpha} .
\end{aligned}
$$

Substituting once more for $\frac{w_{i}}{r_{i}}$ in the previous expression yields

$$
\left(\frac{w_{i}}{P_{x i}}\right)^{1-\alpha}=\left(\frac{1}{\beta}-(1-\delta)\right)^{-\alpha}\left(\frac{A_{x i}}{B_{x}}\right)\left(\frac{\left(\frac{T_{m i}}{\pi_{i i}}\right)^{\frac{1}{\theta}}}{\gamma B_{m}}\right)^{\frac{1-\nu_{x}}{\nu_{m}}} .
$$

Solve for the aggregate capital-labor ratio

$$
\frac{K_{i}}{L_{i}}=\left(\frac{\frac{\alpha}{1-\alpha}}{\left(\frac{1}{\beta}-(1-\delta)\right)^{-\frac{1}{1-\alpha}}}\right)\left(\frac{A_{x i}}{B_{x}}\right)^{\frac{1}{1-\alpha}}\left(\frac{\left(\frac{T_{m i}}{\pi_{i i}}\right)^{\frac{1}{\theta}}}{\gamma B_{m}}\right)^{\frac{1-\nu_{x}}{(1-\alpha) \nu_{m}}}
$$

Note that we invoked steady-state conditions, so this expression does not necessarily hold along the transition path.

Income per capita We define (real) income per capita in our model as

$$
y_{i}=\frac{r_{i} K_{i}+w_{i} L_{i}}{L_{i} P_{c i}} .
$$


We invoke conditions from Table C.2 for the remainder of this derivation. Conditions 1-6, 10 , and 11 imply that

$$
\begin{aligned}
r_{i} K_{i}+w_{i} L_{i} & =\frac{w_{i} L_{i}}{1-\alpha} \\
\Rightarrow y_{i} & =\left(\frac{1}{1-\alpha}\right)\left(\frac{w_{i}}{P_{c i}}\right) .
\end{aligned}
$$

To solve for $\frac{w_{i}}{P_{c i}}$, we use condition 16 :

$$
\begin{gathered}
P_{c i}=\frac{B_{c}}{A_{c i}}\left(\frac{r_{i}}{w_{i}}\right)^{\alpha \nu_{c}}\left(\frac{w_{i}}{P_{m i}}\right)^{\nu_{c}} P_{m i} \\
\Rightarrow \frac{P_{c i}}{w_{i}}=\frac{B_{c}}{A_{c i}}\left(\frac{r_{i}}{w_{i}}\right)^{\alpha \nu_{c}}\left(\frac{w_{i}}{P_{m i}}\right)^{\nu_{c}-1} .
\end{gathered}
$$

Substituting equation (D.1) into the previous expression and exploiting the fact that $\frac{w_{i}}{r_{i}}=$ $\left(\frac{1-\alpha}{\alpha}\right)\left(\frac{K_{i}}{L_{i}}\right)$ yields

$$
\begin{aligned}
y_{i} & =\left(\frac{1}{1-\alpha}\right)\left(\frac{w_{i}}{P_{c i}}\right) \\
& =\alpha^{-\alpha}(1-\alpha)^{\alpha-1}\left(\frac{A_{c i}}{B_{c}}\right)\left(\frac{\left(\frac{T_{m i}}{\pi_{i i}}\right)^{\frac{1}{\theta}}}{\gamma B_{m}}\right)^{\frac{1-\nu_{c}}{\theta \nu_{m}}}\left(\frac{K_{i}}{L_{i}}\right)^{\alpha} .
\end{aligned}
$$

Note that this expression holds both in the steady state and along the transition path.

The steady-state income per capita can be expressed more fundamentally by invoking equation (D.4) as

$$
y_{i}=\left(\frac{\left(\frac{1}{\beta}-(1-\delta)\right)^{-\frac{\alpha}{1-\alpha}}}{1-\alpha}\right)\left(\frac{A_{c i}}{B_{c}}\right)\left(\frac{A_{x i}}{B_{x}}\right)^{\frac{\alpha}{1-\alpha}}\left(\frac{\left(\frac{T_{m i}}{\pi_{i i}}\right)^{\frac{1}{\theta}}}{\gamma B_{m}}\right)^{\frac{1-\nu_{c}+\frac{\alpha}{1-\alpha}\left(1-\nu_{x}\right)}{\nu_{m}}} .
$$




\section{E Solution algorithm for the model with endogenous trade imbalances}

In this Appendix, we describe the algorithm for computing the equilibrium transition path in the model with adjustment costs to capital and endogenous trade imbalances. We first make some housekeeping remarks regarding the capital accumulation technology.

We work with an inverse capital accumulation technology for convenience, which is given by

$$
X_{i t}=\Phi\left(K_{i t+1}, K_{i t}\right)=\left(\frac{1}{\chi}\right)^{\frac{1}{\mu}}\left(K_{i t+1}-(1-\delta) K_{i t}\right)^{\frac{1}{\mu}} K_{i t}^{\frac{\mu-1}{\mu}} .
$$

We use the derivatives of the investment function, with respect to future and current capital, as given by

$$
\begin{aligned}
& \Phi_{1}\left(K^{\prime}, K\right)=\left(\frac{1}{\chi}\right)^{\frac{1}{\mu}}\left(\frac{1}{\mu}\right)\left(\frac{K^{\prime}}{K}-(1-\delta)\right)^{\frac{1-\mu}{\mu}} \\
& \Phi_{2}\left(K^{\prime}, K\right)=\left(\frac{1}{\chi}\right)^{\frac{1}{\mu}}\left(\frac{1}{\mu}\right)\left(\frac{K^{\prime}}{K}-(1-\delta)\right)^{\frac{1-\mu}{\mu}}\left((\mu-1) \frac{K^{\prime}}{K}-\mu(1-\delta)\right) .
\end{aligned}
$$

\section{E.1 Computing the steady-state equilibrium in the model with trade imbalances}

We compute the initial steady-state equilibrium using the same method as in the balanced trade model, with a modification to condition 23 in Table C.1. In particular, the RRR must account for the cost of adjusting the capital stock so that it becomes

$$
r_{i}=\left(\frac{\Phi_{1 i}}{\beta}+\Phi_{2 i}\right) P_{x i}
$$

Note that in steady state, when we set $\chi=\delta^{1-\mu}$ so that there are no adjustment costs in steady state (i.e., $X_{i}=\delta K_{i}$ ), then $\Phi_{1}=\frac{1}{\mu}$ and $\Phi_{2}=\delta-\frac{1}{\mu}$.

In general, in models with trade imbalances, the steady state is not independent of the transition path that leads up to that steady state. In our model, we treat the initial steady state as independent of the prior transition and compute the transition from that steady state. As a result, the new steady state is determined jointly with the equilibrium transition path. 


\section{E.2 Computing the equilibrium transition path in model with trade imbalances}

The equilibrium transition path consists of the following objects: $\left\{\vec{w}_{t}\right\}_{t=1}^{T},\left\{\vec{r}_{t}\right\}_{t=1}^{T},\left\{q_{t}\right\}_{t=1}^{T}$, $\left\{\vec{P}_{c t}\right\}_{t=1}^{T},\left\{\vec{P}_{m t}\right\}_{t=1}^{T},\left\{\vec{P}_{x t}\right\}_{t=1}^{T},\left\{\vec{C}_{t}\right\}_{t=1}^{T},\left\{\vec{X}_{t}\right\}_{t=1}^{T},\left\{\vec{K}_{t}\right\}_{t=1}^{T+1},\left\{\vec{B}_{t}\right\}_{t=1}^{T},\left\{\overrightarrow{\mathcal{A}}_{t}\right\}_{t=1}^{T+1},\left\{\vec{Y}_{c t}\right\}_{t=1}^{T},\left\{\vec{Y}_{m t}\right\}_{t=1}^{T}$, $\left\{\vec{Y}_{x t}\right\}_{t=1}^{T},\left\{\vec{K}_{c t}\right\}_{t=1}^{T},\left\{\vec{K}_{m t}\right\}_{t=1}^{T},\left\{\vec{K}_{x t}\right\}_{t=1}^{T},\left\{\vec{L}_{c t}\right\}_{t=1}^{T},\left\{\vec{L}_{m t}\right\}_{t=1}^{T},\left\{\vec{L}_{x t}\right\}_{t=1}^{T},\left\{\vec{M}_{c t}\right\}_{t=1}^{T},\left\{\vec{M}_{m t}\right\}_{t=1}^{T}$, $\left\{\vec{M}_{x t}\right\}_{t=1}^{T},\left\{\overrightarrow{\vec{\pi}}_{t}\right\}_{t=1}^{T}$ (The double-arrow notation on $\overrightarrow{\vec{\pi}}_{t}$ is used to indicate that this is an $I \times I$ matrix in each period $t$ ). Table E.1 provides a list of equilibrium conditions that these objects must satisfy.

In this environment, the world interest rate is strictly nominal. That is, in the model, the prices map into current units, as opposed to constant units. In other words, the model can be rewritten so that all prices are quoted in time-1 units (like an Arrow-Debreu world) with the world interest rate of zero and the equilibrium would yield identical quantities. Since our choice of numéraire is world GDP in each period, the world interest rate reflects the relative valuation of world GDP at two points in time. This interpretation is useful in guiding the solution procedure.

The solution procedure boils down to two iterations. First, we guess a set of nominal investment rates at each point in time for every country. Given these investment rates, we adapt the algorithm of Sposi (2012) and iterate on the wages and the world interest rate to pin down the solution to the endogenous trade imbalances. Then we go back and update the nominal investment rates that satisfy the Euler equation for the optimal rate of capital accumulation.

To begin, we take the initial capital stock, $K_{i 1}$ as given in each country.

(i) Guess a path for nominal investment rates $\left\{\vec{\rho}_{t}\right\}_{t=1}^{T}$.

(ii) Guess the entire path for wages $\left\{\vec{w}_{t}\right\}_{t=1}^{T}$ across countries and the world interest rate $\left\{q_{t}\right\}_{t=2}^{T}$, such that $\sum_{i} \frac{w_{i t} L_{i t}}{1-\alpha}=1(\forall t)$.

(iii) In period 1 , set $\vec{r}_{1}=\left(\frac{\alpha}{1-\alpha}\right)\left(\frac{\vec{w}_{1} \vec{L}}{\vec{K}_{1}}\right)$ since the initial stock of capital is predetermined. Compute prices $P_{c 1}, P_{x 1}$, and $P_{m 1}$ simultaneously using conditions 16,17 , and 18 in Table E.1. Solve for physical investment, $X_{1}$, using

$$
X_{i t}=\rho_{i t} \frac{w_{i t} L_{i t}+r_{i t} K_{i t}}{P_{x i t}},
$$

and then solve for the next-period capital stock, $K_{2}$, using condition 22. Repeat this 
Table E.1: Dynamic equilibrium conditions in model with trade imbalances

\begin{tabular}{|c|c|c|}
\hline 1 & $r_{i t} K_{c i t}=\alpha \nu_{c} P_{c i t} Y_{c i t}$ & $\forall(i, t)$ \\
\hline 2 & $r_{i t} K_{m i t}=\alpha \nu_{m} P_{m i t} Y_{m i t}$ & $\forall(i, t)$ \\
\hline 3 & $r_{i t} K_{x i t}=\alpha \nu_{x} P_{x i t} Y_{x i t}$ & $\forall(i, t)$ \\
\hline 4 & $w_{i t} L_{c i t}=(1-\alpha) \nu_{c} P_{c i t} Y_{c i t}$ & $\forall(i, t)$ \\
\hline 5 & $w_{i t} L_{m i t}=(1-\alpha) \nu_{m} P_{m i t} Y_{m i t}$ & $\forall(i, t)$ \\
\hline 6 & $w_{i t} L_{x i t}=(1-\alpha) \nu_{x} P_{x i t} Y_{x i t}$ & $\forall(i, t)$ \\
\hline 7 & $P_{m i t} M_{c i t}=\left(1-\nu_{c}\right) P_{c i t} Y_{c i t}$ & $\forall(i, t)$ \\
\hline 8 & $P_{m i t} M_{m i t}=\left(1-\nu_{m}\right) P_{m i t} Y_{m i t}$ & $\forall(i, t)$ \\
\hline 9 & $P_{m i t} M_{x i t}=\left(1-\nu_{x}\right) P_{x i t} Y_{x i t}$ & $\forall(i, t)$ \\
\hline 10 & $K_{c i t}+K_{m i t}+K_{x i t}=K_{i t}$ & $\forall(i, t)$ \\
\hline 11 & $L_{c i t}+L_{m i t}+L_{x i t}=L_{i t}$ & $\forall(i, t)$ \\
\hline 12 & $M_{c i t}+M_{m i t}+M_{x i t}=M_{i t}$ & $\forall(i, t)$ \\
\hline 13 & $C_{i t}=Y_{\text {cit }}$ & $\forall(i, t)$ \\
\hline 14 & $\sum_{j=1}^{I} P_{m j t} M_{j t} \pi_{j i t}=P_{m i t} Y_{m i t}$ & $\forall(i, t)$ \\
\hline 15 & $X_{i t}=Y_{x i t}$ & $\forall(i, t)$ \\
\hline 16 & $P_{c i t}=\left(\frac{1}{A_{c i}}\right)\left(\frac{r_{i t}}{\alpha \nu_{c}}\right)^{\alpha \nu_{c}}\left(\frac{w_{i t}}{(1-\alpha) \nu_{c}}\right)^{(1-\alpha) \nu_{c}}\left(\frac{P_{m i t}}{1-\nu_{c}}\right)^{1-\nu_{c}}$ & $\forall(i, t)$ \\
\hline 17 & $P_{m i t}=\gamma\left[\sum_{j=1}^{I}\left(u_{m j t} d_{i j t}\right)^{-\theta} T_{m j t}\right]^{-\frac{1}{\theta}}$ & $\forall(i, t)$ \\
\hline 18 & $P_{x i t}=\left(\frac{1}{A_{x i}}\right)\left(\frac{r_{i t}}{\alpha \nu_{x}}\right)^{\alpha \nu_{x}}\left(\frac{w_{i t}}{(1-\alpha) \nu_{x}}\right)^{(1-\alpha) \nu_{x}}\left(\frac{P_{m i t}}{1-\nu_{x}}\right)^{1-\nu_{x}}$ & $\forall(i, t)$ \\
\hline 19 & $\pi_{i j t}=\frac{\left(u_{m j t} d_{i j t}\right)^{-\theta} T_{m j t}}{\sum_{i=1}^{I}\left(u_{m j t} d_{i j t}\right)^{-\theta} T_{m j t}}$ & $\forall(i, j, t)$ \\
\hline 20 & $P_{c i t} C_{i t}+P_{x i t} X_{i t}+B_{i t}=r_{i t} K_{i t}+w_{i t} L_{i t}+q_{t} \mathcal{A}_{i t}$ & $\forall(i, t)$ \\
\hline 21 & $\mathcal{A}_{i t+1}=\mathcal{A}_{i t}+B_{i t}$ & $\forall(i, t)$ \\
\hline 22 & $K_{i t+1}=(1-\delta) K_{i t}+\chi X_{i t}^{\mu} K_{i t}^{1-\mu}$ & $\forall(i, t)$ \\
\hline 23 & $\frac{C_{i t+1}}{C_{i t}}=\beta^{\sigma}\left(\frac{\frac{r_{i t+1}}{P_{x i t+1}}-\Phi_{2}\left(K_{i t+2}, K_{i t+1}\right)}{\Phi_{1}\left(K_{i t+1,}, K_{i t}\right)}\right)^{\sigma}\left(\frac{P_{x i t+1} / P_{c i t+1}}{P_{x i t} / P_{c i t}}\right)^{\sigma}$ & $\forall(i, t)$ \\
\hline 24 & $\frac{C_{i t+1}}{C_{i t}}=\beta^{\sigma}\left(\frac{1+q_{t+1}}{P_{c i t+1} / P_{c i t}}\right)^{\sigma}$ & $\forall(i, t)$ \\
\hline 25 & $B_{i t}=P_{m i t} Y_{m i t}-P_{m i t} M_{i t}+q_{t} \mathcal{A}_{i t}$ & $\forall(i, t)$ \\
\hline & te: The term $u_{m j t}=\left(\frac{r_{j t}}{\alpha \nu_{m}}\right)^{\alpha \nu_{m}}\left(\frac{w_{j t}}{(1-\alpha) \nu_{m}}\right)^{(1-\alpha) \nu_{m}}$ & $\left.\frac{m j t}{\nu_{m}}\right)^{1-\nu_{m}}$ \\
\hline
\end{tabular}


set of calculations for period 2, then for period 3 , and continue all the way through period $T$. To complete this step, compute the bilateral trade shares $\left\{\overrightarrow{\vec{\pi}}_{t}\right\}_{t=1}^{T}$ using condition 19.

(iv) This step is slightly more involved. We show how to compute the path for consumption and bond purchases by solving the intertemporal problem of the household. This is done in three steps. First, we derive the lifetime budget constraint. Second, we derive the fraction of lifetime wealth allocated to consumption at each period $t$. And third, we recover the sequences for bond purchases and the stock of NFAs.

Deriving the lifetime budget constraint To begin, compute the lifetime budget constraint for the representative household (omitting country subscripts for now). Begin with the period budget constraint from condition 20 and combine it with the NFA accumulation technology in condition 21 to get

$$
\mathcal{A}_{t+1}=r_{t} K_{t}+w_{t} L_{t}-P_{c t} C_{t}-P_{x t} X_{t}+\left(1+q_{t}\right) \mathcal{A}_{t} .
$$

Iterate the period budget constraint forward through time and derive a lifetime budget constraint. At time $t=1$, the NFA position, $A_{i 1}>0$, is given. Next, compute the NFA position at time $t=2$ :

$$
\mathcal{A}_{2}=r_{1} K_{1}+w_{1} L_{1}-P_{c 1} C_{1}-P_{x 1} X_{1}+\left(1+q_{1}\right) \mathcal{A}_{1}
$$

Similarly, compute the NFA position at time $t=3$, but do it so that it is in terms of the initial NFA position.

$$
\begin{aligned}
\mathcal{A}_{3} & =r_{2} K_{2}+w_{2} L_{2}-P_{c 2} C_{2}-P_{x 2} X_{2}+\left(1+q_{2}\right) \mathcal{A}_{2} \\
\Rightarrow \mathcal{A}_{3} & =r_{2} K_{2}+w_{2} L_{2}-P_{x 2} X_{2}+\left(1+q_{2}\right)\left(r_{1} K_{1}+w_{1} L_{1}-P_{x 1} X_{1}\right) \\
& -P_{c 2} C_{2}-\left(1+q_{2}\right) P_{c 1} C_{1}+\left(1+q_{2}\right)\left(1+q_{1}\right) \mathcal{A}_{i 1} .
\end{aligned}
$$


Continue to period 4 in a similar way:

$$
\begin{aligned}
\mathcal{A}_{4} & =r_{3} K_{3}+w_{3} L_{3}-P_{c 3} C_{3}-P_{x 3} X_{3}+\left(1+q_{3}\right) \mathcal{A}_{3} \\
\Rightarrow \mathcal{A}_{4} & =r_{3} K_{3}+w_{3} L_{3}-P_{x 3} X_{3} \\
& +\left(1+q_{3}\right)\left(r_{2} K_{2}+w_{2} L_{2}-P_{x 2} X_{2}\right) \\
& +\left(1+q_{3}\right)\left(1+q_{2}\right)\left(r_{1} K_{1}+w_{1} L_{1}-P_{x 1} X_{1}\right) \\
& -P_{c 3} C_{3}-\left(1+q_{3}\right) P_{c 2} C_{2}-\left(1+q_{3}\right)\left(1+q_{2}\right) P_{c 1} C_{1}+\left(1+q_{3}\right)\left(1+q_{2}\right)\left(1+q_{1}\right) \mathcal{A}_{1} .
\end{aligned}
$$

Before proceeding, it will be useful to define $\left(1+\mathcal{Q}_{t}\right) \equiv \prod_{n=1}^{t}\left(1+q_{n}\right)$ :

$$
\begin{aligned}
\Rightarrow \mathcal{A}_{4} & =\frac{\left(1+\mathcal{Q}_{3}\right)\left(r_{3} K_{3}+w_{3} L_{3}-P_{x 3} X_{3}\right)}{\left(1+\mathcal{Q}_{3}\right)} \\
& +\frac{\left(1+\mathcal{Q}_{3}\right)\left(r_{2} K_{2}+w_{2} L_{2}-P_{x 2} X_{2}\right)}{\left(1+\mathcal{Q}_{2}\right)} \\
& +\frac{\left(1+\mathcal{Q}_{3}\right)\left(r_{1} K_{1}+w_{1} L_{1}-P_{x 1} X_{1}\right)}{\left(1+\mathcal{Q}_{1}\right)} \\
& -\frac{\left(1+\mathcal{Q}_{3}\right) P_{c 3} C_{3}}{\left(1+\mathcal{Q}_{3}\right)} \\
& -\frac{\left(1+\mathcal{Q}_{3}\right) P_{c 2} C_{2}}{\left(1+\mathcal{Q}_{2}\right)} \\
& -\frac{\left(1+\mathcal{Q}_{3}\right) P_{c 1} C_{1}}{\left(1+\mathcal{Q}_{1}\right)} \\
& +\left(1+\mathcal{Q}_{3}\right) \mathcal{A}_{1} .
\end{aligned}
$$

By induction, for any time $t$,

$$
\begin{aligned}
\mathcal{A}_{t+1} & =\sum_{n=1}^{t} \frac{\left(1+\mathcal{Q}_{t}\right)\left(r_{n} K_{n}+w_{n} L_{n}-P_{x n} X_{n}\right)}{\left(1+\mathcal{Q}_{n}\right)}-\sum_{n=1}^{t} \frac{\left(1+\mathcal{Q}_{t}\right) P_{c n} C_{n}}{\left(1+\mathcal{Q}_{n}\right)}+\left(1+\mathcal{Q}_{t}\right) \mathcal{A}_{1} \\
\Rightarrow \mathcal{A}_{t+1} & =\left(1+\mathcal{Q}_{t}\right)\left(\sum_{n=1}^{t} \frac{r_{n} K_{n}+w_{n} L_{n}-P_{x n} X_{n}}{\left(1+\mathcal{Q}_{n}\right)}-\sum_{n=1}^{t} \frac{P_{c n} C_{n}}{\left(1+\mathcal{Q}_{n}\right)}+\mathcal{A}_{1}\right) .
\end{aligned}
$$


Finally, observe the previous expression as of $t=T$ and rearrange terms to derive the lifetime budget constraint:

$$
\sum_{n=1}^{T} \frac{P_{c n} C_{n}}{\left(1+\mathcal{Q}_{n}\right)}=\underbrace{\sum_{n=1}^{T} \frac{r_{n} K_{n}+w_{n} L_{n}-P_{x n} X_{n}}{\left(1+\mathcal{Q}_{n}\right)}+\mathcal{A}_{1}-\frac{\mathcal{A}_{T+1}}{\left(1+\mathcal{Q}_{T}\right)}}_{W} .
$$

In the lifetime budget constraint (E.1), $W$ denotes the net present value of lifetime wealth, taking both the initial and terminal NFA positions as given.

Solving for the path of consumption Next, compute how the net present value of lifetime wealth is optimally allocated throughout time. The Euler equation (condition 24) implies the following relationship between consumption in any two periods $t$ and $n$ :

$$
\begin{gathered}
C_{n}=\left(\frac{L_{n}}{L_{t}}\right) \beta^{\sigma(n-t)}\left(\frac{1+\mathcal{Q}_{n}}{1+\mathcal{Q}_{t}}\right)^{\sigma}\left(\frac{P_{c t}}{P_{c n}}\right)^{\sigma} C_{t} \\
\Rightarrow \frac{P_{c n} C_{n}}{1+\mathcal{Q}_{n}}=\left(\frac{L_{n}}{L_{t}}\right) \beta^{\sigma(n-t)}\left(\frac{1+\mathcal{Q}_{n}}{1+\mathcal{Q}_{t}}\right)^{\sigma-1}\left(\frac{P_{c t}}{P_{c n}}\right)^{\sigma-1} \frac{P_{t} C_{t}}{1+\mathcal{Q}_{t}} .
\end{gathered}
$$

Since equation E.1 implies that $\sum_{n=1}^{T} \frac{P_{c i n} C_{i n}}{1+\mathcal{Q}_{n}}=W$, rearrange the previous expression (putting country subscripts back in) to obtain

$$
\frac{P_{c i t} C_{i t}}{1+\mathcal{Q}_{i t}}=\underbrace{\left(\frac{L_{i t} \beta^{\sigma t}\left(1+\mathcal{Q}_{i t}\right)^{\sigma-1} P_{c i t}^{1-\sigma}}{\sum_{n=1}^{T} L_{i n} \beta^{\sigma n}\left(1+\mathcal{Q}_{i n}\right)^{\sigma-1} P_{c i n}^{1-\sigma}}\right)}_{\xi_{i t}} W_{i}
$$

That is, each period the household spends a share $\xi_{i t}$ of lifetime wealth on consumption, with $\sum_{t=1}^{T} \xi_{i t}=1$ for all $i$. Note that $\xi_{i t}$ depends only on prices.

Computing bond purchases and the NFA positions In period 1, take as given consumption spending, investment spending, capital income, labor income, and net income from the initial NFA position to solve for net bond purchases $\left\{\vec{B}_{t}\right\}_{t=1}^{T}$ using the period budget constraint in condition 20. Solve for the NFA position in period 2 using condition 21. Then given income and spending in period 2, recover the net bond purchases in period 2 and compute the NFA position for period 3. Continue this 
process through all points in time.

Trade balance condition We compute an excess demand equation as in Alvarez and Lucas (2007), but instead of imposing that net exports equal 0 in each country, we impose that net exports equal the current account less net foreign income from asset holding. That is,

$$
Z_{i t}^{w}\left(\left\{\vec{w}_{t}, q_{t}\right\}_{t=1}^{T}\right)=\frac{P_{m i t} Y_{m i t}-P_{m i t} M_{i t}-B_{i t}+q_{t} \mathcal{A}_{i t}}{w_{i t}} .
$$

Condition 25 requires that $Z_{i t}^{w}\left(\left\{\vec{w}_{t}, \vec{r}_{t}\right\}_{t=1}^{T}\right)=0$ for all $(i, t)$ in equilibrium. If this is different from 0 in at least some country at some point in time, update the wages as follows:

$$
\Lambda_{i t}^{w}\left(\left\{\vec{w}_{t}, q_{t}\right\}_{t=1}^{T}\right)=w_{i t}\left(1+\psi \frac{Z_{i t}^{w}\left(\left\{\vec{w}_{t}, q_{t}\right\}_{t=1}^{T}\right)}{L_{i t}}\right)
$$

is the updated guess for the wages, where $\psi$ is chosen to be sufficiently small so that $\Lambda^{w}>0$.

Normalizing model units The next part of this step is updating the equilibrium world interest rate. Recall that the numéraire is defined to be world GDP at each point in time: $\sum_{i=1}^{I}\left(r_{i t} K_{i t}+w_{i t} L_{i t}\right)=1(\forall t)$. For an arbitrary sequence of $\left\{q_{t+1}\right\}_{t=1}^{T}$, this condition need not hold. As such, update the world interest rate as

$$
1+q_{t}=\frac{\sum_{i=1}^{I}\left(r_{i t-1} K_{i t-1}+\Lambda_{i t-1}^{w} L_{i t-1}\right)}{\sum_{i=1}^{I}\left(r_{i t} K_{i t}+\Lambda_{i t}^{w} L_{i t}\right)} \text { for } t=2, \ldots, T
$$

The inputs for capital and the rental rate of capital are computed in step (ii), while the input for wages is the updated values $\Lambda^{w}$ above. The world interest rate in the initial period, $q_{1}$, has no influence on the model other than scaling the initial NFA position $q_{1} A_{i 1}$; that is, it is purely nominal. As such, we set $q_{1}=\frac{1-\beta}{\beta}$ (the interest rate that prevails in a steady state) and choose $A_{i 1}$ so that $q_{1} A_{i 1}$ matches the desired initial NFA position in current prices.

Having updated the wages and the world interest rate, return to step (ii) and perform each step again. Iterate through this procedure until the excess demand is sufficiently 
close to 0 . In the computations, we find that our preferred convergence metric,

$$
\max _{t=1}^{T}\left\{\max _{i=1}^{I}\left\{\left|Z_{i t}^{w}\left(\left\{\vec{w}_{t}, q_{t}\right\}_{t=1}^{T}\right)\right|\right\}\right\}
$$

converges roughly monotonically toward 0 . This provides the solution to a "subequilibrium" for an exogenously specified nominal investment rate.

(v) The last step of the algorithm is to update the nominal investment rate. Until now, the Euler equation for investment in physical capital, condition 23, has not been used. As such, we compute a "Euler equation residual" as

$$
Z_{i t}^{r}\left(\left\{\overrightarrow{\rho_{t}}\right\}_{t=1}^{T}\right)=\beta^{\sigma}\left(\frac{\frac{r_{i t+1}}{P_{x i t+1}}-\Phi_{2}\left(K_{i t+2}, K_{i t+1}\right)}{\Phi_{1}\left(K_{i t+1}, K_{i t}\right)}\right)^{\sigma}\left(\frac{P_{x i t+1} / P_{c i t+1}}{P_{x i t} / P_{c i t}}\right)^{\sigma}-\left(\frac{C_{i t+1}}{C_{i t}}\right) .
$$

Condition 23 requires that $Z_{i t}^{r}\left(\left\{\vec{\rho}_{t}\right\}_{t=1}^{T}\right)=0$ for all $(i, t)$ in equilibrium. We update the nominal investment rates as

$$
\Lambda_{i t}^{r}\left(\left\{\overrightarrow{\rho_{t}}\right\}_{t=1}^{T}\right)=\rho_{i t}\left(1+\psi Z_{i t}^{r}\left(\left\{\overrightarrow{\rho_{t}}\right\}_{t=1}^{T}\right)\right)
$$

To update $\rho_{i T}$, we need to define $\Phi_{2}\left(K_{i T+2}, K_{i T+1}\right)$, which is simply its steady-state value, $\Phi_{2}^{\star}=\delta-\frac{1}{\mu}$, which serves as a boundary condition for the transition path of capital stocks.

Given the updated sequence of nominal investment rates, return to step (i) and repeat. Continue the iterations until $\max _{t=1}^{T}\left\{\max _{i=1}^{I}\left\{\left|Z_{i t}^{r}\left(\left\{\vec{\rho}_{t}\right\}_{t=1}^{T}\right)\right|\right\}\right\}$ is sufficiently close to 0 .

\section{F List of countries and their gains from trade}

Table F.1: Gains from trade (\%) following uniform reduction in frictions by 55 percent

\begin{tabular}{l|ccc|cc|c|c|cc}
\hline \hline & Model & \multicolumn{2}{|c|}{$\mathbf{1}$} & \multicolumn{2}{c|}{$\mathbf{2}$} & $\mathbf{3}$ & $\mathbf{4}$ & \multicolumn{2}{c}{$\mathbf{5}$} \\
\hline Country & Dyn & SS & Dyn & SS & Dyn & Dyn & Dyn & SS \\
\hline Armenia & 24.2 & 29.3 & 46.9 & 77.8 & 47.2 & 35.8 & 36.0 & 61.7 \\
Australia & 10.9 & 13.2 & 20.5 & 34.5 & 20.8 & 16.2 & 16.2 & 31.6 \\
Austria & & 14.3 & 17.3 & 26.5 & 44.6 & 26.9 & 20.8 & 20.8 & 38.7 \\
Bahamas & 21.7 & 26.2 & 40.9 & 67.2 & 40.8 & 31.3 & 31.4 & 54.9 \\
Baltics & 17.4 & 21.1 & 32.4 & 54.4 & 32.9 & 25.2 & 25.3 & 45.5 \\
Bangladesh & 16.7 & 20.2 & 30.8 & 51.5 & 31.1 & 24.0 & 24.1 & 43.6 \\
\hline (Continued) & & \multicolumn{7}{|c|}{}
\end{tabular}


Table F.1 - Continued

\begin{tabular}{|c|c|c|c|c|c|c|c|c|}
\hline \multirow{2}{*}{$\begin{array}{ll} & \text { Model } \\
\text { Country } & \end{array}$} & \multicolumn{2}{|c|}{1} & \multicolumn{2}{|c|}{2} & \multirow{2}{*}{$\begin{array}{c}3 \\
\text { Dyn }\end{array}$} & \multirow{2}{*}{$\begin{array}{c}4 \\
\text { Dyn }\end{array}$} & \multicolumn{2}{|c|}{5} \\
\hline & Dyn & SS & Dyn & SS & & & Dyn & SS \\
\hline Barbados & 26.6 & 32.3 & 52.6 & 86.6 & 52.7 & 39.8 & 40.0 & 67.9 \\
\hline Belarus & 14.2 & 17.2 & 26.9 & 45.3 & 27.3 & 21.0 & 21.1 & 39.1 \\
\hline Belize & 28.6 & 34.7 & 55.8 & 91.6 & 55.7 & 42.0 & 42.3 & 71.4 \\
\hline Benin & 22.3 & 27.1 & 43.4 & 72.1 & 43.7 & 33.2 & 33.4 & 57.7 \\
\hline Bhutan & 21.4 & 26.0 & 40.4 & 66.5 & 40.4 & 31.0 & 31.0 & 54.4 \\
\hline Brazil & 7.6 & 9.2 & 14.3 & 24.3 & 14.6 & 11.4 & 11.4 & 24.4 \\
\hline Bulgaria & 19.6 & 23.8 & 36.8 & 61.6 & 37.3 & 28.4 & 28.6 & 50.5 \\
\hline Burundi & 13.1 & 15.9 & 24.8 & 42.0 & 25.3 & 19.5 & 19.6 & 36.8 \\
\hline Côte d'Ivoire & 21.0 & 25.4 & 40.0 & 66.3 & 40.2 & 30.7 & 30.8 & 53.9 \\
\hline Cabo Verde & 21.8 & 26.5 & 42.2 & 70.4 & 42.7 & 32.4 & 32.6 & 56.6 \\
\hline Cambodia & 19.7 & 23.8 & 36.3 & 60.1 & 36.4 & 28.0 & 28.1 & 49.8 \\
\hline Cameroon & 19.3 & 23.4 & 37.1 & 61.8 & 37.4 & 28.6 & 28.7 & 50.7 \\
\hline Canada & 10.3 & 12.4 & 18.8 & 31.5 & 19.0 & 14.8 & 14.8 & 29.7 \\
\hline Central African Rep. & 13.3 & 16.2 & 25.4 & 42.8 & 25.8 & 19.9 & 20.0 & 37.3 \\
\hline Chile & 16.1 & 19.5 & 30.0 & 49.9 & 30.2 & 23.3 & 23.4 & 42.5 \\
\hline China, Hong Kong, Macao & 6.5 & 7.9 & 11.1 & 19.1 & 11.5 & 8.9 & 8.9 & 20.7 \\
\hline Colombia & 14.6 & 17.7 & 27.6 & 45.9 & 27.8 & 21.5 & 21.5 & 39.8 \\
\hline Costa Rica & 21.2 & 25.7 & 40.8 & 67.0 & 40.7 & 31.2 & 31.3 & 54.8 \\
\hline Cyprus & 20.3 & 24.6 & 39.5 & 66.0 & 40.0 & 30.4 & 30.6 & 53.4 \\
\hline Czech Rep. & 15.4 & 18.6 & 28.5 & 47.8 & 28.9 & 22.3 & 22.4 & 41.0 \\
\hline Denmark & 15.7 & 19.0 & 29.2 & 48.9 & 29.6 & 22.8 & 22.8 & 41.7 \\
\hline Dominican Rep. & 13.2 & 16.0 & 23.5 & 39.2 & 23.7 & 18.4 & 18.4 & 35.1 \\
\hline Ecuador & 20.6 & 25.0 & 39.0 & 64.4 & 39.0 & 30.0 & 30.0 & 52.8 \\
\hline Egypt & 17.9 & 21.7 & 33.6 & 56.1 & 33.9 & 26.0 & 26.1 & 46.7 \\
\hline Ethiopia & 18.1 & 21.9 & 35.4 & 59.1 & 35.7 & 27.3 & 27.5 & 48.8 \\
\hline Fiji & 21.3 & 25.8 & 40.9 & 67.7 & 41.0 & 31.4 & 31.5 & 54.9 \\
\hline Finland & 16.3 & 19.7 & 30.2 & 50.6 & 30.6 & 23.5 & 23.6 & 42.9 \\
\hline France & 11.3 & 13.7 & 21.0 & 35.6 & 21.4 & 16.6 & 16.6 & 32.3 \\
\hline Georgia & 24.0 & 29.2 & 46.4 & 76.8 & 46.6 & 35.4 & 35.6 & 61.1 \\
\hline Germany & 11.1 & 13.4 & 20.3 & 34.4 & 20.7 & 16.0 & 16.1 & 31.5 \\
\hline Greece & 16.7 & 20.2 & 31.8 & 53.5 & 32.3 & 24.7 & 24.9 & 44.8 \\
\hline Guatemala & 15.0 & 18.2 & 27.6 & 46.0 & 27.8 & 21.5 & 21.6 & 39.8 \\
\hline Honduras & 20.0 & 24.2 & 37.8 & 62.1 & 37.7 & 29.0 & 29.0 & 51.3 \\
\hline Hungary & 11.5 & 13.9 & 21.2 & 35.9 & 21.6 & 16.7 & 16.8 & 32.5 \\
\hline Iceland & 24.5 & 29.8 & 47.2 & 78.1 & 47.5 & 36.0 & 36.2 & 62.1 \\
\hline India & 9.1 & 11.0 & 16.6 & 28.3 & 17.0 & 13.2 & 13.3 & 27.2 \\
\hline Indonesia & 13.6 & 16.5 & 25.9 & 43.4 & 26.2 & 20.3 & 20.3 & 37.9 \\
\hline Iran & 11.9 & 14.4 & 20.7 & 34.9 & 21.0 & 16.3 & 16.4 & 31.9 \\
\hline Ireland & 16.2 & 19.6 & 29.4 & 49.0 & 29.6 & 22.9 & 22.9 & 41.9 \\
\hline Israel & 19.9 & 24.0 & 37.6 & 62.2 & 37.7 & 28.9 & 29.0 & 51.2 \\
\hline Italy & 11.6 & 14.1 & 21.4 & 36.4 & 21.9 & 16.9 & 17.0 & 32.9 \\
\hline Jamaica & 21.6 & 26.1 & 41.8 & 68.9 & 41.8 & 32.0 & 32.1 & 55.9 \\
\hline Jap & 7.1 & 8.6 & 12.8 & 21.8 & 13.1 & 10.2 & 10.3 & 22.6 \\
\hline Jordan & 20.1 & 24.4 & 38.5 & 64.0 & 38.8 & 29.6 & 29.8 & 52.3 \\
\hline Kyrgyzstan & 21.1 & 25.6 & 40.2 & 66.7 & 40.4 & 30.8 & 31.0 & 54.1 \\
\hline Lesotho & 16.0 & 19.3 & 30.5 & 50.6 & 30.6 & 23.6 & 23.7 & 43.1 \\
\hline Madagascar & 19.1 & 23.2 & 36.5 & 60.9 & 36.9 & 28.2 & 28.3 & 50.1 \\
\hline Malawi & 22.1 & 26.9 & 40.8 & 68.0 & 41.2 & 31.3 & 31.5 & 54.8 \\
\hline Maldives & 25.4 & 30.9 & 45.8 & 76.1 & 46.2 & 35.0 & 35.2 & 60.5 \\
\hline Mauritius & 23.5 & 28.5 & 44.4 & 73.8 & 44.8 & 34.0 & 34.2 & 59.0 \\
\hline Mexico & 6.5 & 7.9 & 12.0 & 20.8 & 12.5 & 9.7 & 9.7 & 21.8 \\
\hline Morocco & 20.0 & 24.3 & 38.4 & 63.9 & 38.7 & 29.6 & 29.7 & 52.2 \\
\hline Mozambique & 22.1 & 26.8 & 42.7 & 71.0 & 43.1 & 32.7 & 32.9 & 57.1 \\
\hline Nepal & 15.8 & 19.2 & 29.3 & 48.8 & 29.5 & 22.8 & 22.8 & 41.8 \\
\hline New Zealand & 17.4 & 21.1 & 32.9 & 54.7 & 33.1 & 25.5 & 25.6 & 45.8 \\
\hline Pakistan & 12.0 & 14.5 & 21.1 & 35.6 & 21.5 & 16.6 & 16.7 & 32.4 \\
\hline Paraguay & 21.5 & 26.0 & 40.8 & 67.4 & 40.9 & 31.3 & 31.4 & 54.8 \\
\hline Peru & 14.9 & 18.0 & 27.6 & 46.2 & 27.9 & 21.5 & 21.6 & 39.8 \\
\hline
\end{tabular}

(Continued) 
Table F.1 - Continued

\begin{tabular}{l|cc|cc|c|c|cc}
\hline \hline & Model & \multicolumn{2}{|c|}{$\mathbf{1}$} & \multicolumn{2}{c|}{$\mathbf{2}$} & $\mathbf{3}$ & $\mathbf{4}$ & \multicolumn{2}{c}{$\mathbf{5}$} \\
\hline Country & Dyn & SS & Dyn & SS & Dyn & Dyn & Dyn & SS \\
\hline Philippines & 16.0 & 19.3 & 29.3 & 48.8 & 29.5 & 22.8 & 22.9 & 41.8 \\
Poland & 14.0 & 17.0 & 26.0 & 43.8 & 26.4 & 20.4 & 20.4 & 38.1 \\
Portugal & 16.3 & 19.7 & 30.3 & 50.7 & 30.7 & 23.6 & 23.7 & 43.0 \\
Rep. of Korea & 13.3 & 16.1 & 23.9 & 40.0 & 24.2 & 18.8 & 18.8 & 35.6 \\
Rep. of Moldova & 20.9 & 25.3 & 40.0 & 66.8 & 40.5 & 30.8 & 31.0 & 54.0 \\
Romania & 17.4 & 21.1 & 32.4 & 54.2 & 32.8 & 25.1 & 25.3 & 45.4 \\
Russian Federation & 12.5 & 15.2 & 23.4 & 39.6 & 23.9 & 18.4 & 18.5 & 35.1 \\
Rwanda & 11.8 & 14.3 & 22.0 & 37.3 & 22.5 & 17.4 & 17.4 & 33.5 \\
Saint Vincent and the Grenadines & 28.1 & 34.2 & 56.0 & 92.7 & 56.4 & 42.3 & 42.7 & 71.9 \\
Sao Tome and Principe & 20.8 & 25.3 & 39.4 & 65.8 & 39.9 & 30.3 & 30.5 & 53.4 \\
Senegal & 23.5 & 28.5 & 46.2 & 76.8 & 46.6 & 35.3 & 35.5 & 61.0 \\
South Africa & 15.3 & 18.6 & 29.3 & 49.0 & 29.6 & 22.8 & 22.9 & 41.8 \\
Spain & 11.7 & 14.2 & 21.4 & 36.3 & 21.9 & 16.9 & 17.0 & 32.8 \\
Sri Lanka & 17.4 & 21.1 & 32.1 & 53.6 & 32.4 & 24.9 & 25.0 & 45.1 \\
Sweden & 14.8 & 17.9 & 27.7 & 46.5 & 28.1 & 21.6 & 21.7 & 40.0 \\
Switzerland & 15.4 & 18.7 & 28.4 & 47.5 & 28.7 & 22.1 & 22.2 & 40.8 \\
TFYR of Macedonia & 20.3 & 24.6 & 38.4 & 64.2 & 38.9 & 29.6 & 29.8 & 52.3 \\
Thailand & 17.4 & 21.0 & 32.2 & 53.6 & 32.4 & 25.0 & 25.0 & 45.1 \\
Tunisia & 21.2 & 25.7 & 40.3 & 67.1 & 40.7 & 31.0 & 31.1 & 54.4 \\
Turkey & 14.4 & 17.5 & 26.3 & 44.4 & 26.8 & 20.6 & 20.7 & 38.5 \\
USA & 5.7 & 6.9 & 10.6 & 18.3 & 11.0 & 8.5 & 8.5 & 20.0 \\
Uganda & 11.8 & 14.3 & 22.0 & 37.4 & 22.5 & 17.4 & 17.5 & 33.5 \\
Ukraine & 15.9 & 19.3 & 30.3 & 50.9 & 30.7 & 23.6 & 23.7 & 43.0 \\
United Kingdom & 12.7 & 15.4 & 23.4 & 39.5 & 23.8 & 18.4 & 18.5 & 35.1 \\
United Rep. of Tanzania & 22.5 & 27.3 & 43.7 & 72.7 & 44.1 & 33.5 & 33.7 & 58.1 \\
Uruguay & 19.0 & 23.0 & 36.6 & 60.9 & 36.9 & 28.3 & 28.4 & 50.1 \\
Venezuela & 15.5 & 18.7 & 29.1 & 48.4 & 29.2 & 22.6 & 22.7 & 41.5 \\
Viet Nam & 19.7 & 23.9 & 36.3 & 60.2 & 36.5 & 28.0 & 28.1 & 49.7 \\
Yemen & 22.1 & 26.9 & 41.9 & 69.3 & 42.0 & 32.1 & 32.2 & 56.0 \\
\hline \hline
\end{tabular}

Note: "Dyn" refers to dynamic gains and "SS" refers to steady-state gains. Model 1 is the model with an exogenous nominal investment rate and a fixed relative price of investment. Model 2 adds the endogenous relative price of investment to model 1 . Model 3 adds the endogenous nominal investment rate to model 2. Model 4 adds adjustment costs to capital accumulation to model 3. Model 5 adds the endogenous trade imbalances to model 4. Steady-state gains are identical in models 2, 3, and 4. The group "Southeast Europe" is an aggregate of Albania, Bosnia and Herzegovina, Croatia, Montenegro, and Serbia. 